\title{
Summary of Ice Shape Geometric Fidelity Studies on an Iced Swept Wing
}

\author{
Brian S. Woodard ${ }^{1}$ \\ University of Illinois at Urbana-Champaign, Urbana, Illinois, 61801 USA \\ Andy P. Broeren ${ }^{2}$ \\ NASA John H. Glenn Research Center, Cleveland, Ohio, 44135 USA \\ Sam Lee ${ }^{3}$ \\ Vantage Partners, LLC, Cleveland, Ohio, 44135 USA \\ Christopher W. Lum ${ }^{4}$ and Michael B. Bragg ${ }^{5}$ \\ University of Washington, Seattle, Washington, 98195 USA
}

\begin{abstract}
Understanding the aerodynamic impact of swept-wing ice accretions is a crucial component of the design of modern aircraft. Computer-simulation tools are commonly used to approximate ice shapes, so the necessary level of detail or fidelity of those simulated ice shapes must be understood relative to high-fidelity representations of the ice. Previous tests were performed in the NASA Icing Research Tunnel to acquire high-fidelity ice shapes. Some of those ice shapes are based on aircraft certification requirements. From this database, full-span artificial ice shapes were designed and manufactured for both an 8.9\%-scale and 13.3\%-scale semispan wing model of the CRM65 which has been established as the full-scale baseline for this sweptwing project. These models were tested in the Walter H. Beech wind tunnel at Wichita State University and at the ONERA F1 facility, respectively. The data collected in the Wichita St. University wind tunnel provided a low-Reynolds number baseline study while the pressurized F1 facility produced data over a wide range of Reynolds and Mach numbers with the highest Reynolds number studied being approximately $R e=11.9 \times 10^{6}$. Three different fidelity representations were created based on three different icing conditions. Lower-fidelity ice shapes were created by lofting a smooth ice shape between cross-section cuts of the high-fidelity ice shape. Grit roughness was

1 Research Associate, Dept. of Aerospace Engineering, 306 Talbot Lab, 104 S. Wright St., Member AIAA.

2 Research Aerospace Engineer, Icing Branch, 21000 Brookpark Rd., MS 11-2, Associate Fellow AIAA.

3 Engineer V, Icing Branch, 21000 Brookpark Rd., MS 11-2, Senior Member AIAA.

4 Research Assistant Professor, William E. Boeing Department of Aeronautics and Astronautics, Guggenheim Hall Room 211, Box 352400, Member AIAA.

5 Frank and Julie Jungers Dean, College of Engineering, and Professor, William E. Boeing Department of Aeronautics and Astronautics, University of Washington; Loew Hall Room 371, Box 352180, AIAA fellow.
\end{abstract}


attached to this smooth ice shape as another fidelity variant. The data indicate that the geometric fidelity of the ice shapes resulted in significant differences in lift and drag. These results were similar at both facilities over the wide range of test conditions utilized.

\section{Nomenclature}

$$
\begin{aligned}
& C_{D} \quad=\text { drag coefficient } \\
& C_{D, \min }=\text { minimum drag coefficient } \\
& C_{D, 0.6}=\text { drag coefficient at } C_{L}=0.6 \\
& C_{L} \quad=\text { lift coefficient } \\
& C_{L, \max }=\text { maximum lift coefficient } \\
& C_{L, \text { use }} \quad=\text { usable lift coefficient } \\
& C_{M} \quad=\text { quarter-chord mean aerodynamic chord pitching moment } \\
& \mathrm{C}_{M, \text { min }} \quad=\text { minimum quarter-chord mean aerodynamic chord pitching moment } \\
& C_{p} \quad=\text { model surface pressure coefficient } \\
& \mathrm{CRM}=\text { Common Research Model } \\
& \text { CRM65 }=65 \% \text { scale version of the CRM (full-scale reference for this project) } \\
& \text { LWC = icing cloud liquid water content } \\
& M \quad=\text { freestream Mach number } \\
& M A C \quad=\text { mean aerodynamic chord } \\
& \text { MCCS = maximum combined cross section } \\
& \text { MVD = median volumetric diameter of icing cloud drop distribution } \\
& \text { Re }=\text { freestream Reynolds number based on mean aerodynamic chord } \\
& \text { RLE = removable leading edge } \\
& \text { WSU = Wichita State University } \\
& x \quad=\text { wing streamwise coordinate } \\
& y=\text { wing spanwise coordinate } \\
& z=\text { wing thickness coordinate } \\
& \alpha=\text { model angle of attack } \\
& \alpha_{\text {stall }}=\text { stalling angle of attack, consistent with the maximum lift coefficient } \\
& \alpha_{\text {use }} \quad=\text { usable angle of attack, consistent with the usable lift coefficient }
\end{aligned}
$$




\section{Introduction}

Understanding the effects of ice accretion on the aerodynamic performance of large scale, swept wings is a complicated problem affecting the design and certification of transport aircraft. These effects on highly three-dimensional wings are currently not well understood and present a significant challenge to airframe manufacturers, certification authorities, and research organizations. In an effort to understand this problem, a large collaborative research program has been sponsored by NASA, the Office National d'Etudes et Recherches Aérospatiales (ONERA), and the Federal Aviation Administration (FAA). Broeren et al. ${ }^{1}$ describes the objectives of this project in more detail. Two of the primary goals involve creating a database of realistic publicallyavailable, swept-wing ice accretions and performing aerodynamic assessments of the aerodynamic effects of those ice accretions. Aircraft manufacturers and regulators are increasingly interested in simulation tools for aircraft icing, but validation cases are necessary for these types of ice accretions. These validation ice shapes and aerodynamic performance measurements are provided by this project for swept wings. Extensive past research into the aerodynamic performance effects of ice accretion has primarily focused on airfoils and straight wings which are generally twodimensional. Bragg et al. ${ }^{2}$ reviewed this research topic and classified ice accretions by their aerodynamic effect. A similar effort is likely necessary for swept-wing icing, but further aerodynamic test results are necessary.

Swept-wing ice accretions are extremely complex geometrically. Many conditions result in highly three-dimensional ice accretions that are often referred to as "scallops" or "lobster tails" due to their appearance and the substantial spanwise variations in the ice. Icing simulation tools like those currently being developed by NASA and ONERA have been applied through this research project ${ }^{3,4}$ but are unable to capture these three-dimensional variations. However, the level of fidelity to which these variations need to be captured in order to accurately predict the aerodynamics is not fully understood. One way to quantify that fidelity requirement is to test various fidelity representations of the ice shapes for their aerodynamic performance effects. As part of this collaborative research effort, an ice accretion database for large-scale swept wings has been created based on a series of tests in the Icing Research Tunnel (IRT) at the NASA Glenn Research Center. ${ }^{5}$ These ice accretions form the basis for the fidelity variations studied in this paper. 
In aircraft icing research, ice accretions are commonly recreated to be attached to airfoils or wings for testing in dry-air wind tunnels. Generally, these recreated representations are referred to as artificial ice shapes. Throughout this work, several fidelity variations of these artificial ice shapes will be explored. A past NASA-ONERA research project investigated geometric fidelities associated with developing these artificial ice shapes. ${ }^{6}$ During that project, modern methods of capturing three-dimensional geometries were not available, but more recently a method for creating high-fidelity artificial ice shapes has been validated using 3-D laser scanning and rapidprototype manufacturing. ${ }^{7}$ That methodology was utilized for this project. With these capabilities applied to the swept-wing ice accretion database, numerous artificial ice shapes are available for wind tunnel testing for aerodynamic performance effects. Both low- and high-Reynolds number aerodynamic testing have been performed using these ice shapes. The ice accretion database and the aerodynamic wind tunnel models are all based on the Common Research Model (CRM). ${ }^{8-11}$ For this project, the full-scale geometry is a $65 \%$ scale version of the CRM, designated here as CRM65. ${ }^{1}$ The design of the icing tunnel models is described by Fujiwara et al. ${ }^{12}$ Low-Reynolds number testing was performed using an 8.9\% scale model of the CRM65, and the high-Reynolds number testing utilized a $13.3 \%$ scale model. Broeren et al., ${ }^{13}$ Camello et al., ${ }^{14}$ and Lum et al. ${ }^{15}$ have presented results related to the low-Reynolds number aerodynamic testing with Camello et al. making a preliminary investigation into the ice shape fidelity effects relating to the aerodynamics.

This paper will present the results of fidelity-variation studies for three ice accretions that have been tested at low- and high-Reynolds number. The primary data used for these comparisons come from the force balance measuring the integrated performance of the wing, but additional data from the model surface pressures can provide further insight regarding the flowfield. Performance parameters are defined for comparing these various ice fidelity simulations based on the data. Comparisons are made between lift- and drag-based performance parameters over a large range of Reynolds numbers representing two different scale wind tunnel models tested at different facilities. Companion papers by Broeren et al., ${ }^{16}$ Lee et al., ${ }^{17}$ and Sandu et al. ${ }^{18}$ provide additional details regarding other aspects of these wind tunnel tests. Additionally, this paper will summarize the icing aerodynamic simulation process along with the terminology that has been developed for naming conventions for these various fidelity ice shapes. 


\section{Wind-Tunnel Facility, Model, and Experimental Methods}

\section{A. Wind-Tunnel Facilities}

The majority of the experimental data described in this work were collected at the ONERA F1 pressurized wind tunnel located at the Fauga-Mauzac Center in southern France. The closedreturn tunnel can be pressurized to $56 \mathrm{psi}$ and has a test section approximately 11.5 -ft high x 14.8 $\mathrm{ft}$ wide. The pressurization capability provides independent Reynolds and Mach number control over a range of $R e=1.6 \times 10^{6}$ to $11.9 \times 10^{6}$ and $M=0.09$ to 0.34 for the tests described. Not all possible combinations of Reynolds and Mach number in that range are achievable in the facility simultaneously. Broeren et al. ${ }^{16}$ describe the complete test matrix and other details of the facility in more depth, so only the basic description of the facility for understanding the tests is provided here. A maximum of thirteen combinations of Reynolds and Mach number were utilized for testing various icing configurations. For some configurations, the conditions were omitted in order to optimize the limited test time in the wind tunnel. Angle of attack sweeps were performed with a continuous change in pitch angle at a constant rate of $0.1 \mathrm{deg} / \mathrm{sec}$. The model angle of attack was varied from - 6 deg up to 25 deg except in cases where dynamic forces limited the maximum angle of attack or a clear local maximum in lift coefficient was measured. During each of those angle of attack sweeps, the aerodynamic forces were measured along with the surface pressures. Broeren et al. ${ }^{16}$ also describe the data acquisition system in greater detail including the load ranges and associated uncertainty for each of calculated aerodynamic performance parameters. The normal and axial force values are measured using an external balance below the floor of wind tunnel that turns with the model as the angle of attack changes. The lift and drag are then calculated in the usual way to determine the forces in the coordinate system based relative to the free-stream velocity.

Since the data were collected as the model rotated continuously about the pitch axis, a custom post-processing routine was developed in order to conditionally average the continuous data into discrete data points. The plots in the paper utilize this post-processed data with 0.5 deg. angle of attack increments. The pitching-moment coefficient was referenced to the quarter-cord of the mean aerodynamic chord. Previously published work for this swept-wing icing research project referenced the pitching-moment coefficient to a different location on the wing. In

particular several papers and reports ${ }^{13,14,19}$ summarizing lower-Reynolds number tests with the same model geometry used a different reference location. 
The lower Reynolds number wind-tunnel tests were performed at the Walter H. Beech Memorial Wind Tunnel on the campus of Wichita State University (WSU). This closed-return wind tunnel operates at atmospheric pressure, so Reynolds number and Mach number aerodynamic effects cannot be independently investigated. The test section measures 7 -ft high $\mathrm{x} 10$-ft wide. The data presented were measured at approximately $R e=1.6 \times 10^{6}$ and $M=0.17$ or $\operatorname{Re}=2.4 \times 10^{6}$ and $M=0.26$. The details of the experimental setup along with an uncertainty analysis can be found in Woodard et al. ${ }^{19}$ and the initial wind tunnel tests are described by Broeren et al. ${ }^{13}$ and Camello et al. ${ }^{14}$ The data from the force balance and the surface pressures are acquired in a standard pitch-pause method, so post-processing the data into discrete points is not necessary.

All aerodynamic data $\left(\alpha, C_{L}, C_{M}, C_{D}\right.$ and $\left.C_{p}\right)$ presented in this paper were corrected for wind-tunnel-wall effects. The data from the F1 facility are corrected using an in-house ONERA method that yields two corrections terms, one of which is constant based on the model and wind tunnel geometry and the other proportional to the model lift coefficient. The data collected in the lower-Reynolds number, atmospheric-pressure wind tunnel at WSU are corrected using the procedure for 3D model corrections outlined in Barlow et al. ${ }^{20}$ and implemented by WSU. ${ }^{21}$ The magnitude of the correction to the angle of attack applied in the WSU facility has been reduced relative to past papers and reports related to this project. ${ }^{13,14,19}$ Lee et al. ${ }^{17}$ describe the motivation for the change to the angle of attack correction. In both facilities, the corrections are performed in real-time as part of the data acquisition process. Direct comparisons of aerodynamic performance parameters from the two facilities are avoided in this paper, and only relative effects are presented. However, the companion paper by Lee et al. ${ }^{17}$ provides comparison and analysis of the results from the two different facilities.

\section{B. Wind-Tunnel Models Description}

The two semispan models fabricated for these wind-tunnel tests were based on an $8.9 \%$ and $13.3 \%$ scale version of the CRM65 wing. Due to the facilities for which the models were designed, the $8.9 \%$-scale model is referred to as the WSU model, and the $13.3 \%$-scale model is referred to as the F1 model. Table 1 summarizes the geometric parameters of the wings. The F1 model is exactly $50 \%$ larger than the WSU model. The full-scale, original CRM geometry has a realistic cruise configuration loading applied to the wing resulting in a wing shear similar to

dihedral. ${ }^{11}$ In order to simplify the design of the removable leading edge segments (described 
below), this shearing or "bending" of the wing was removed from the model geometry resulting in an unsheared wing with a straight leading edge across the span of the model. The wing retains the twist and taper of the original CRM. A planform view of the F1 model is shown in Fig. 1 with key dimensions.

Table 1. Summary of 8.9\% and 13.3\% Scale CRM65 Semispan Wing Geometric Parameters

\begin{tabular}{lll}
\hline Wing Parameter & F1 Value $(13.3 \%)$ & WSU Value $(8.9 \%)$ \\
\hline Span, $b$ & $7.5 \mathrm{ft}(90.00$ inches $)$ & $5.0 \mathrm{ft}(60.00$ inches $)$ \\
$M A C$ & $2.08 \mathrm{ft}(25.01$ inches $)$ & $1.39 \mathrm{ft}(16.67$ inches $)$ \\
Area (Geometric) & $13.55 \mathrm{ft}^{2}\left(1951.0 \mathrm{in}^{2}\right)$ & $6.01 \mathrm{ft}^{2}\left(865.3 \mathrm{in}^{2}\right)$ \\
Volume & $2.09 \mathrm{ft}^{3}\left(3604.5 \mathrm{in}^{3}\right)$ & $0.617 \mathrm{ft}^{3}\left(1069 \mathrm{in}^{3}\right)$ \\
Aspect ratio $\dagger$ & 8.3 & 8.3 \\
Taper ratio & 0.23 & 0.23 \\
Root chord & $3.38 \mathrm{ft}(40.50$ inches $)$ & $2.25 \mathrm{ft}(27.00$ inches $)$ \\
Tip chord & $0.77 \mathrm{ft}(9.28$ inches $)$ & $0.52 \mathrm{ft}(6.19$ inches $)$ \\
Root $\alpha$ & $4.4 \mathrm{deg}$. & $4.4 \mathrm{deg}$. \\
Tip $\alpha$ & $-3.8 \mathrm{deg}$. & $-3.8 \mathrm{deg}$. \\
$1 / 4-$ chord sweep angle & $35 \mathrm{deg}$. & $35 \mathrm{deg}$. \\
Leading edge sweep angle & $37.2 \mathrm{deg}$. & $37.2 \mathrm{deg}$. \\
Location of rotation center $\ddagger$ & $x=29.05$ in., $z=0$ & $x=19.37 \mathrm{in} ., z=0$ \\
Location of moment center $\ddagger$ & $x=35.80$ in., $z=0$ & $x=23.87 \mathrm{in} ., z=0$ \\
Location of $0.25 \times M A C \ddagger$ & $x=26.23$ in., $z=0$ & $x=17.49$ in., $z=0$ \\
\hline \hline
\end{tabular}

$\dagger$--While the other parameters in this table are defined specifically for this model, the aspect ratio is defined for a complete airplane configuration using the formula, $\frac{(2 x \text { semispan })^{2}}{2 x \text { area of one wing }}$. $\$-(0,0,0)$ is the wing root-section leading edge at zero angle of attack. 


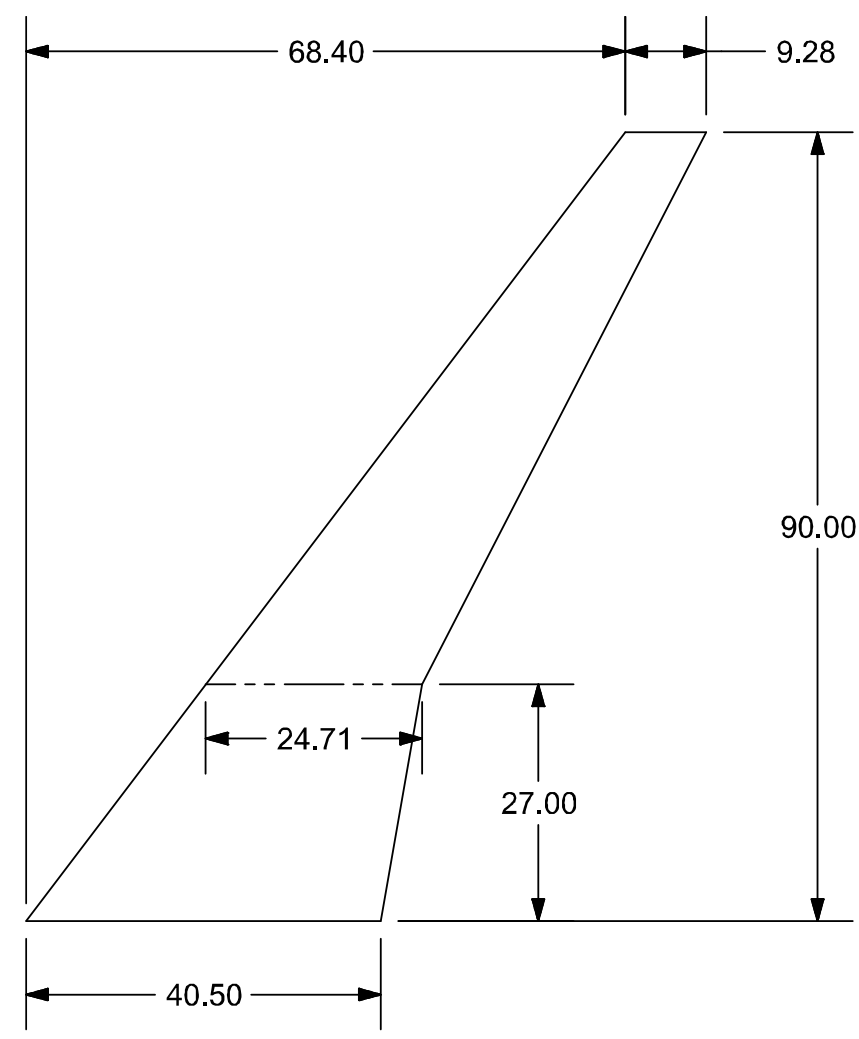

Figure 1. $13.3 \%$ scale (F1 Model) CRM65 semispan wing planform with key dimensions labeled in inches.

For the F1 model, the main body was machined from stainless steel while the removable leading edge components were machined from aluminum. For the WSU model, both the main element and the removable leading edge components were aluminum. The F1 model contained 243 pressure taps in its clean configuration, while the WSU model contained 219. Figure 2 shows photographs of the wing models installed in their respective wind tunnels with circular splitter plates. An artificial ice shape is mounted to the leading edge of the F1 model, and the WSU model is shown in the clean configuration. Below the circular splitter plate shown in the images, a streamlined shroud isolates the wing spar from any aerodynamic loads by covering it. With this arrangement, both the splitter plate and shroud were non-metric meaning the aerodynamic forces were only measured on the wing itself. The designs of the splitter plate and shroud were specifically investigated during a preliminary test campaign utilizing the WSU model prior to the design and fabrication of the F1 model. ${ }^{13,19}$ 

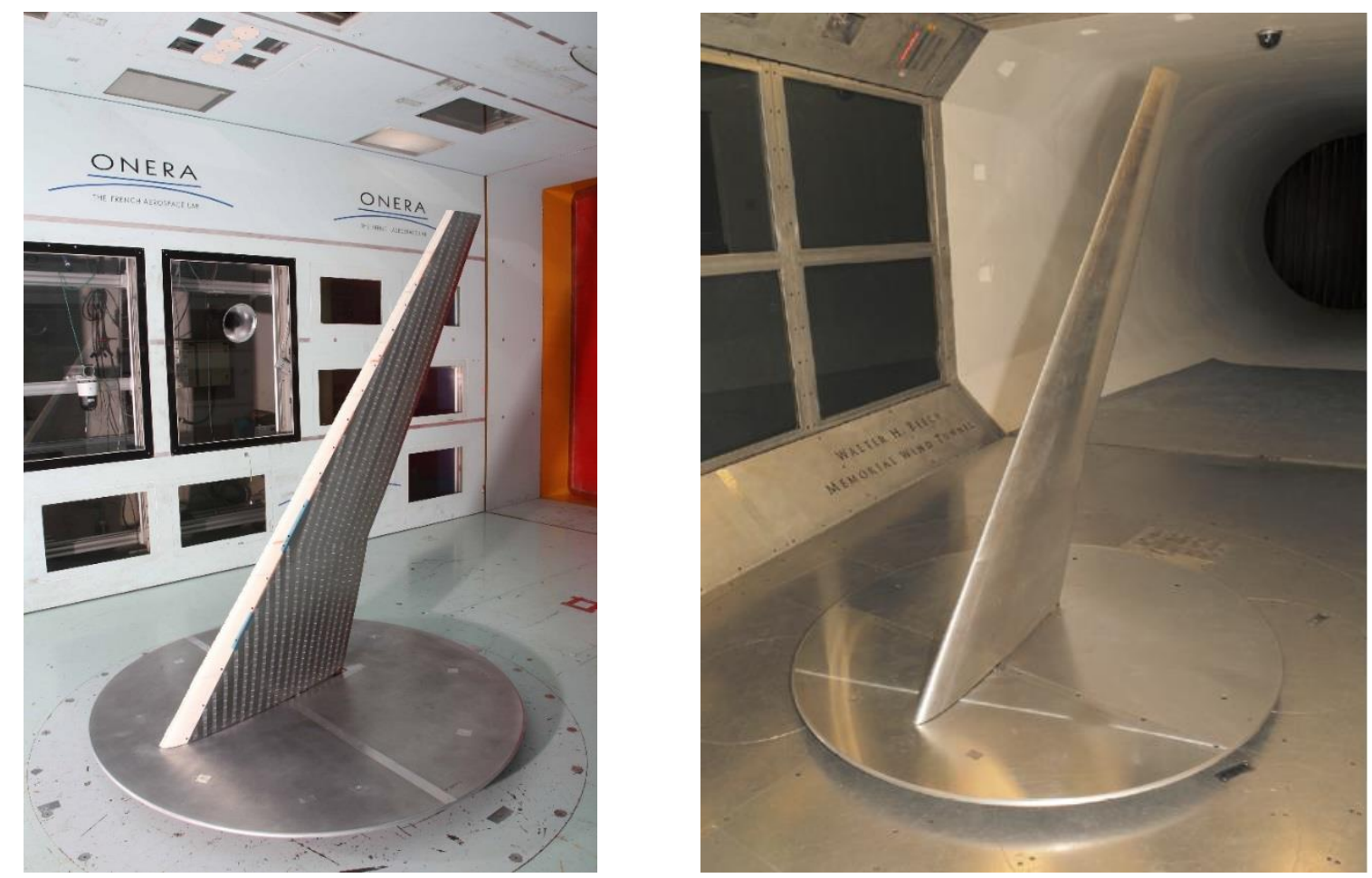

Figure 2. Photographs upper surface of subscale CRM65 semispan wing models installed in their respective wind tunnels; left image shows $13.3 \%$ scale CRM65 semispan wing installed in ONERA F1 test section; right image shows $8.9 \%$ scale CRM65 semispan wing installed in WSU test section.

The model was designed and built with a removable leading edge that allowed artificial ice-shapes to be added to the wing. This approach has been used in previous icing aerodynamic studies $^{6,22,23,24,25}$ and allows for efficient and repeatable changes of the artificial ice-shape configurations. The efficiency was particularly important during this research effort when a large number of ice-shape configurations were investigated in limited test time. The main components of each model were: the main element (including a spar that attached to the force balance); a fullspan clean leading edge; and a partial-span leading edge used for mounting ice shapes. An open channel exists between the main element and any of the leading edge components for routing pressure tubing out through the base of the model to the data acquisition system. The partial-span removable leading edge extended from the root to $83 \%$ of the semispan for the F1 model and from the root to $50 \%$ of the semispan for the WSU model. Both contained a portion of the airfoil contour on the lower surface. Artificial ice shapes were attached to these removable leading edges and covered the entire upper surface of this removable leading edge. Outboard of this partial-span leading edge, the artificial ice shapes were attached directly to the main element. The model is too thin at the outboard portion of the wing to support the addition of a full-span removable leading 
edge. This design does not adversely affect the efficiency or repeatability of the artificial iceshape configuration changes.

The artificial ice shapes were created using a rapid prototype manufacturing (RPM) technique called stereo-lithography (SLA). The SLA process utilizes an ultraviolet laser to solidify liquid polymer resins. The majority of the artificial ice shapes were manufactured from the Somos NeXt brand polymer. Some of the early ice shapes were rapid prototyped using Accura 60. The tolerances are advertised to be about +/- 0.005 inches for this process for either polymer. The Somos NeXt material was selected due to desirable advertised properties associated with the stability of the printed parts. The project potentially requires artificial ice shapes to be in storage for over one year between tests. Early work with SLA products proved challenging with regard to long-term storage. Mitigating exposure to water vapor in the air and ultra-violet radiation has been shown to drastically improve the lifetime of the parts for repeat testing. The process for creating an artificial ice shape involves adding the full-span ice shape to the necessary wing geometry, and then dividing the ice shape into sections. The leading edge was divided into three segments for the F1 model and two segments for the WSU model. All segments were approximately 37.5 inches long. Pressure taps were installed in each of these segments at the same locations as on the clean removable leading edge. The pressure tap holes were included in the RPM design, and then stainless steel tubes were glued into each hole and plumbed to a quick disconnect inside the channel between the removable leading edge and the main element.

The pressure taps in the models were primarily distributed in streamwise rows across the span of the model. On the F1 model, all pressure taps were arranged in these streamwise rows, but on the WSU model, some taps were arranged in rows normal to the leading edge. Other references contain further details on the locations of the $\mathrm{F} 1^{16}$ and $\mathrm{WSU} \mathrm{U}^{20}$ pressure taps. In this work, pressure data are only shown for the F1 model, so Fig. 3 illustrates the locations of the pressure taps on the upper and lower surfaces. The taps in the main element of the model were plumbed with stainless steel tubing from their location on the surface out the root of the model. The routing of the taps in the removable leading edges required a more complicated design. The stainless steel tubing in both the clean leading edge and in the RPM ice leading edges transitioned to plastic tubing and then connected to a Scanivalve quick disconnect fitting. The use of these fittings allowed relatively quick model reconfigurations between clean and various RPM leading edges. 


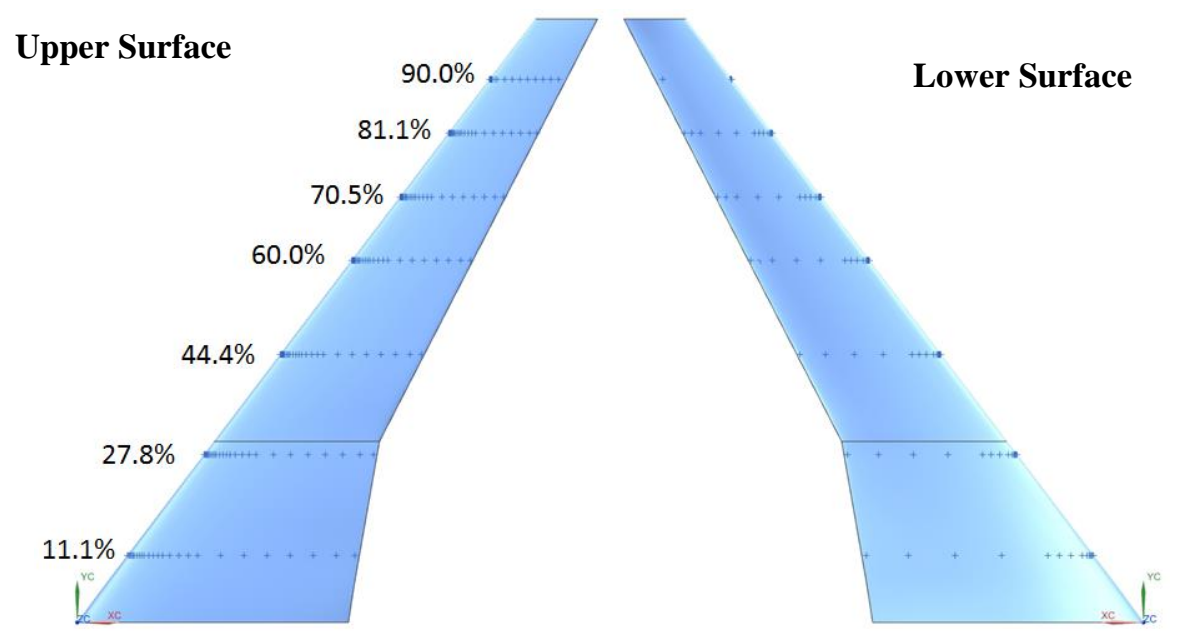

Figure 3. Pressure tap locations on 13.3\% scale CRM65 (F1 model).

\section{Artificial Ice-Shape Configurations}

Throughout this project, many artificial ice-shape configurations have been designed and tested. Camello et al. ${ }^{14}$ summarized the ice shapes that have been tested at WSU. These artificial ice shapes include high-fidelity representations based directly on icing wind tunnel testing and various fidelity representations of those high-fidelity ice shapes or their associated icing conditions. Table 2 shows a subset of the complete icing condition matrix emphasizing the three conditions for which various fidelity ice shapes have been created. For all three of these conditions, different fidelity representations have been designed, built, and tested in either the F1 or WSU facility.

Table 2. Summary of icing conditions for artificial ice shapes tested with varying fidelity

\begin{tabular}{cccccccc}
\hline \hline & $\begin{array}{c}\text { Angle of } \\
\text { Attack } \\
(\mathrm{deg})\end{array}$ & $\begin{array}{c}\text { Speed } \\
(\mathrm{knots})\end{array}$ & $\begin{array}{c}\text { Total } \\
\text { Temp. } \\
\left({ }^{\circ} \mathrm{C}\right)\end{array}$ & $\begin{array}{c}\text { Static } \\
\text { Temp. } \\
\left({ }^{\circ} \mathrm{C}\right)\end{array}$ & $\begin{array}{c}\text { MVD } \\
(\mu \mathrm{m})\end{array}$ & $\begin{array}{c}\text { LWC } \\
\left(\mathrm{g} / \mathrm{m}^{3}\right)\end{array}$ & $\begin{array}{c}\text { Exposure } \\
\text { Time } \\
(\mathrm{min})\end{array}$ \\
\hline Ice Shape Name & 3.7 & 130 & -6.3 & -8.5 & 25 & 1.0 & 29 \\
Maximum Scallop & 3.7 & 130 & -17.9 & -20.1 & 25 & 0.6 & 23 \\
Streamwise/Rime & 3.7 & 130 & -3.1 & -5.3 & 27 & 0.91 & 45 \\
WB33 & & & &
\end{tabular}

Ice-accretion testing was performed in the NASA Icing Research Tunnel using three individual full-scale CRM65 section models. Details of the icing tests associated with this project are provided by Broeren et al. ${ }^{5}$ The three sections, referred to as the Inboard, Midspan, and Outboard, represent $y / b$ of $0.20,0.64$, and 0.83 , respectively. Icing tests were performed for each of the models at the conditions listed in Table 2, and the resulting ice shapes were captured using a 3D laser scanning method. ${ }^{7}$ Full-span ice shapes were then developed from the three laser-scanned 
sections. Camello et al. ${ }^{26}$ describe the process by which the ice is interpolated and extrapolated to cover the entire leading edge of the wing. The specific conditions for the icing tests were nominally based on holding conditions for a CRM65 aircraft in the Code of Federal Regulations, Part 25, Appendix C, Continuous Maximum. However, only the Streamwise/Rime and WB33 ice shapes were exactly scaled from the regulation. The Maximum Scallop conditions resulted from a temperature sweep while holding other conditions constant. Images of the actual ice shapes from the three IRT test models are shown in Figs. 4-6 for the three ice shapes described by Table 2. The names for many of the ice shapes are based on the general appearance of the ice although all of the shapes show significant spanwise variation. The "Maximum Scallop" ice shape has welldefined scallops or lobster tails at all three spanwise stations. The Streamwise/Rime shape shown in Fig. 5 was characterized by large-scale rime feathers, particularly on the Inboard model. The ice on the Midspan and Outboard models was characterized by a main ice shape formed at the attachment line with rime feathers downstream. The WB33 ice shape shown in Fig. 6 was characterized by highly three-dimensional ice features, some of which resembled scallop tips. The name "WB33" was derived from the specific flight condition associated with this case. As later images will illustrate, the overall size of the Maximum Scallop and WB33 ice shapes is similar and much larger than the Streamwise/Rime ice shape.

While the images shown in Figs. 4-6 represent the three dimensionality of the ice shapes well, they do not easily illustrate the size of the ice. Further comparisons are shown in Fig. 7 where the maximum combined cross section (MCCS) is plotted for each of the three ice shapes. The MCCS ${ }^{5}$ was derived from 30 section cuts over a six-inch spanwise segment of the $3 \mathrm{D}$ ice scan. The section cuts were projected onto a single plane and the maximum outer boundary was obtained. The resulting MCCS profile represents the outermost extent of the ice shape over that six-inch segment. The three dimensionality of the ice shapes is not obvious in these MCCS plots, but the size variations are evident. 


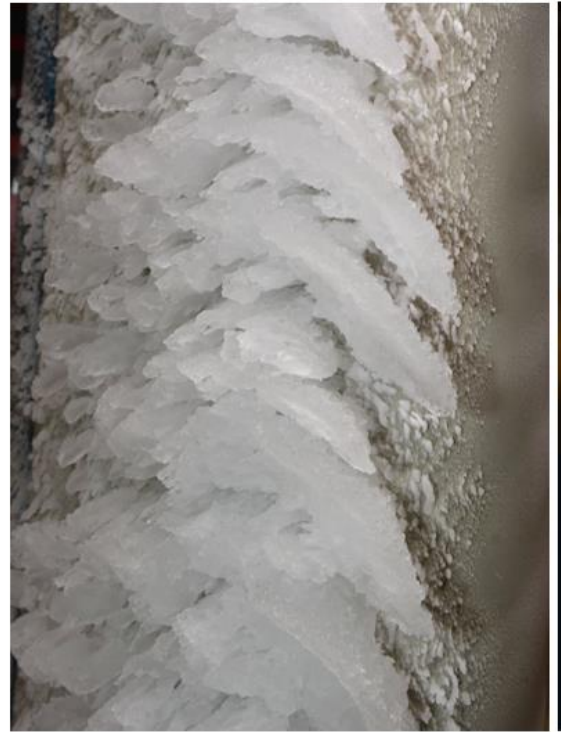

Inboard

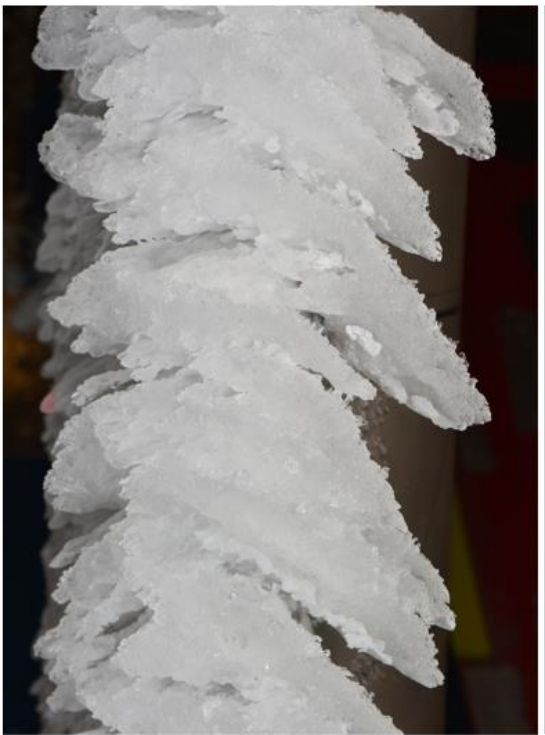

Midspan

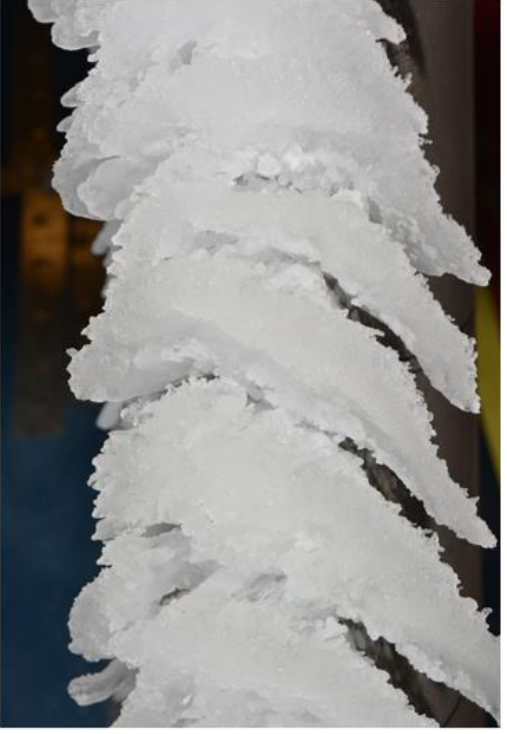

Outboard

Figure 4. Photographs of Maximum Scallop ice shape at three spanwise locations.

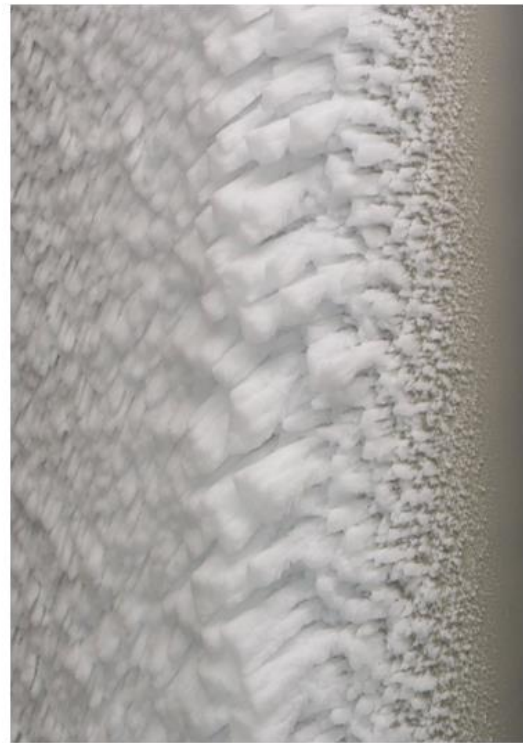

Inboard

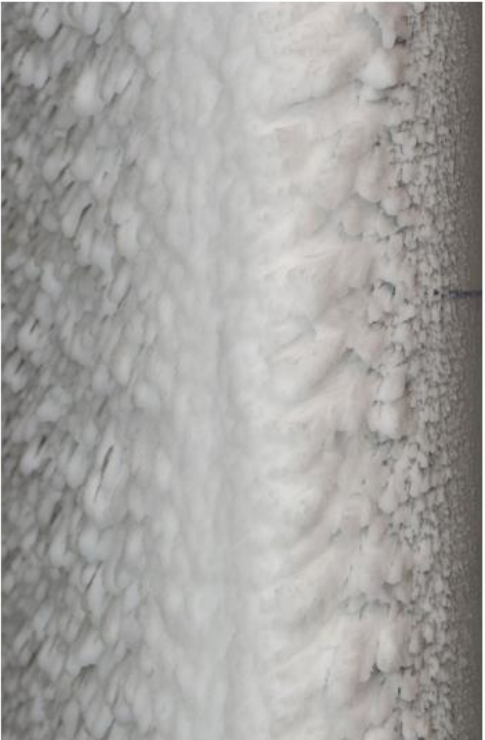

Midspan

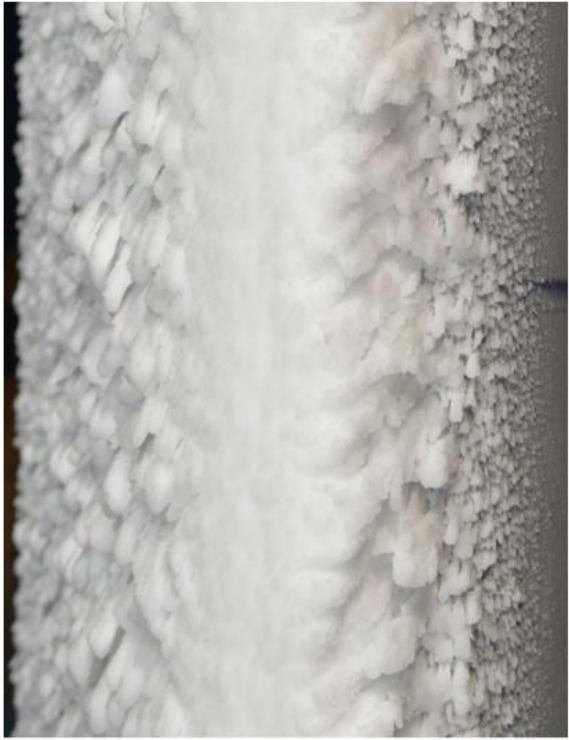

Outboard

Figure 5. Photographs of Streamwise/Rime ice shape at three spanwise locations. 


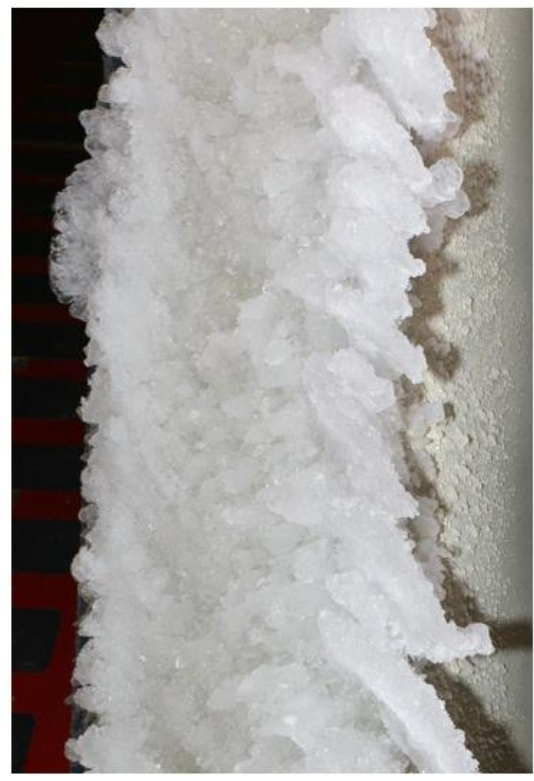

Inboard

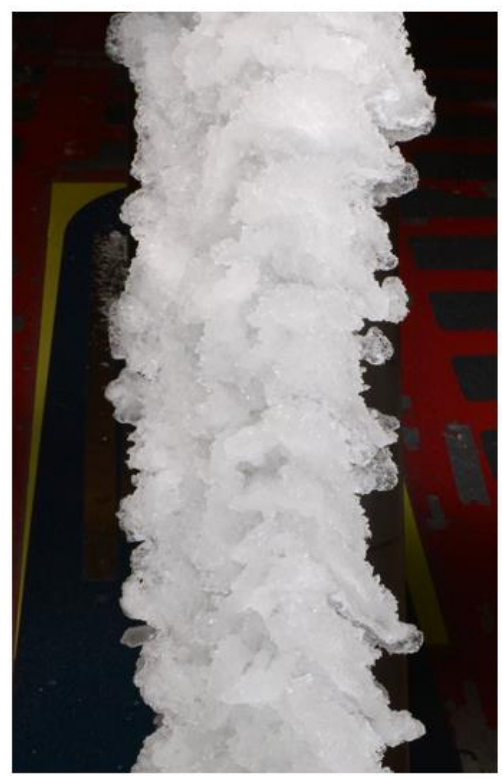

Midspan

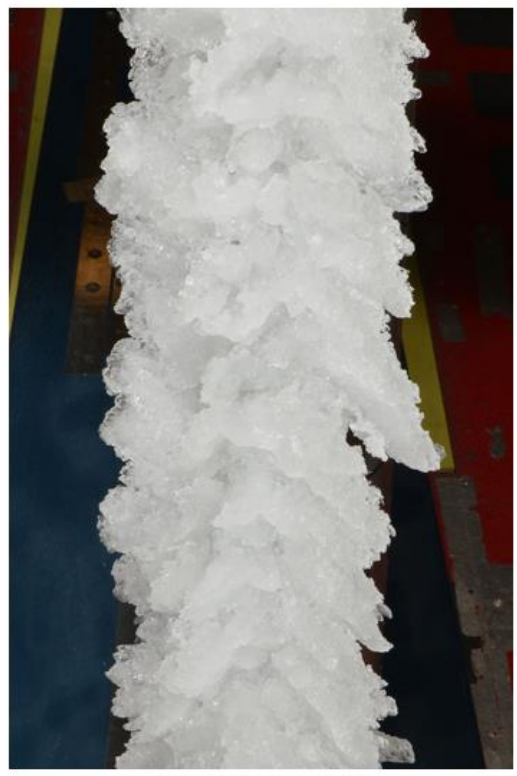

Outboard

Figure 6. Photographs of WB33 ice shape at three spanwise locations.
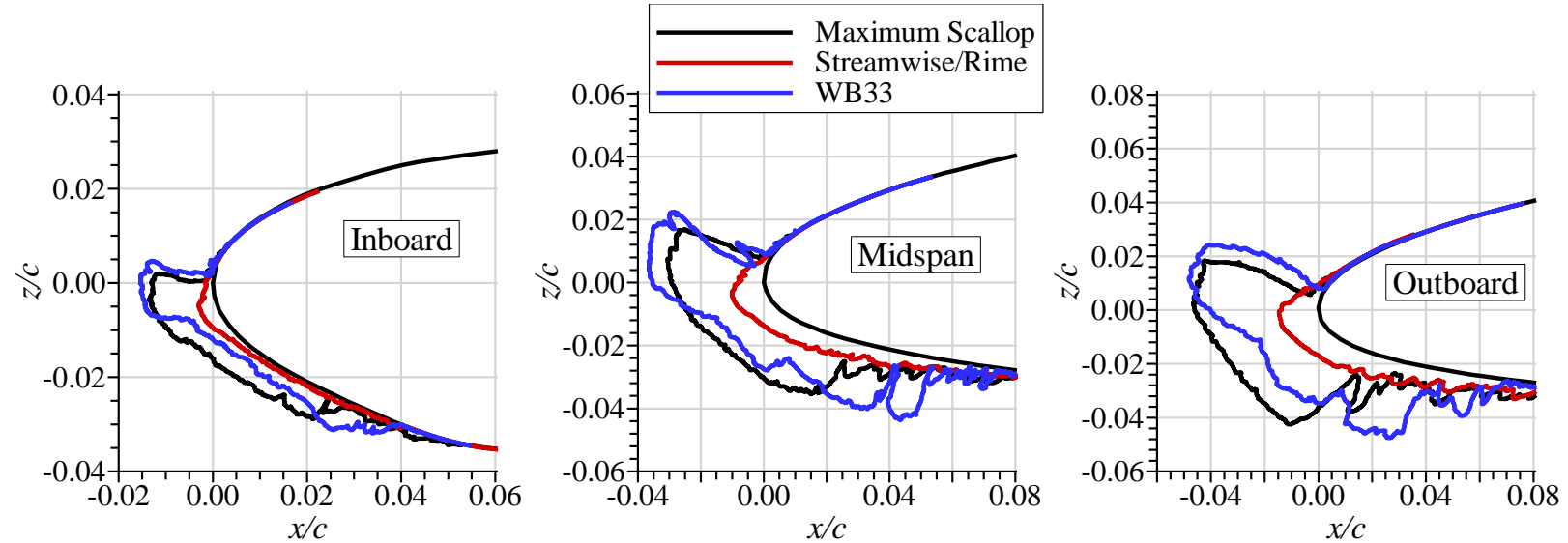

Figure 7. MCCS of Max Scallop, Streamwise/Rime, and WB33 ice shapes.

The full-span ice shapes that are developed from the laser scans contain all of the highly three-dimensional properties of the original ice shape. In terms of fidelity, these ice shapes are called "high fidelity" meaning that they are the most detailed ice shapes available based on current understanding and technology. The limitations of the current method for actual reproduction of the ice shapes are described by Camello et al. ${ }^{26}$ as they describe the details of the process by which the laser scans of the ice shapes are transformed into the wind-tunnel model ice shapes. Various lower fidelity representations can also be created based on the full-span high-fidelity shapes. The ice shapes described as "3D Smooth" are built by taking section cuts along the span, smoothing these cuts, and then lofting them to build a new, full-span ice shape. An example comparison 
between a high fidelity and 3D smooth ice shape is shown in Fig. 8. These ice shapes are spanwise smooth in the sense that no scallops are represented, but they are three dimensional such that the ice horn height and angle vary across the span. Some past publications have described these lowerfidelity ice shapes as "2D Smooth," but that naming convention implies that the cross section of the ice shape does not vary across the span. The ice shapes detailed in this work and described as 3D smooth have substantial spanwise variation as they are derived directly from the high-fidelity ice shapes. They simply do not have the scallop features present in the high-fidelity ice shapes. An additional category of lower-fidelity ice shapes, named "3D Simple" ice shapes, has been developed to investigate the influence of the overall ice shape. The cross section of these 3D simple ice shapes is not based directly on experimental ice shapes and could be a spoiler, backward-facing step, or other geometric-based shape.

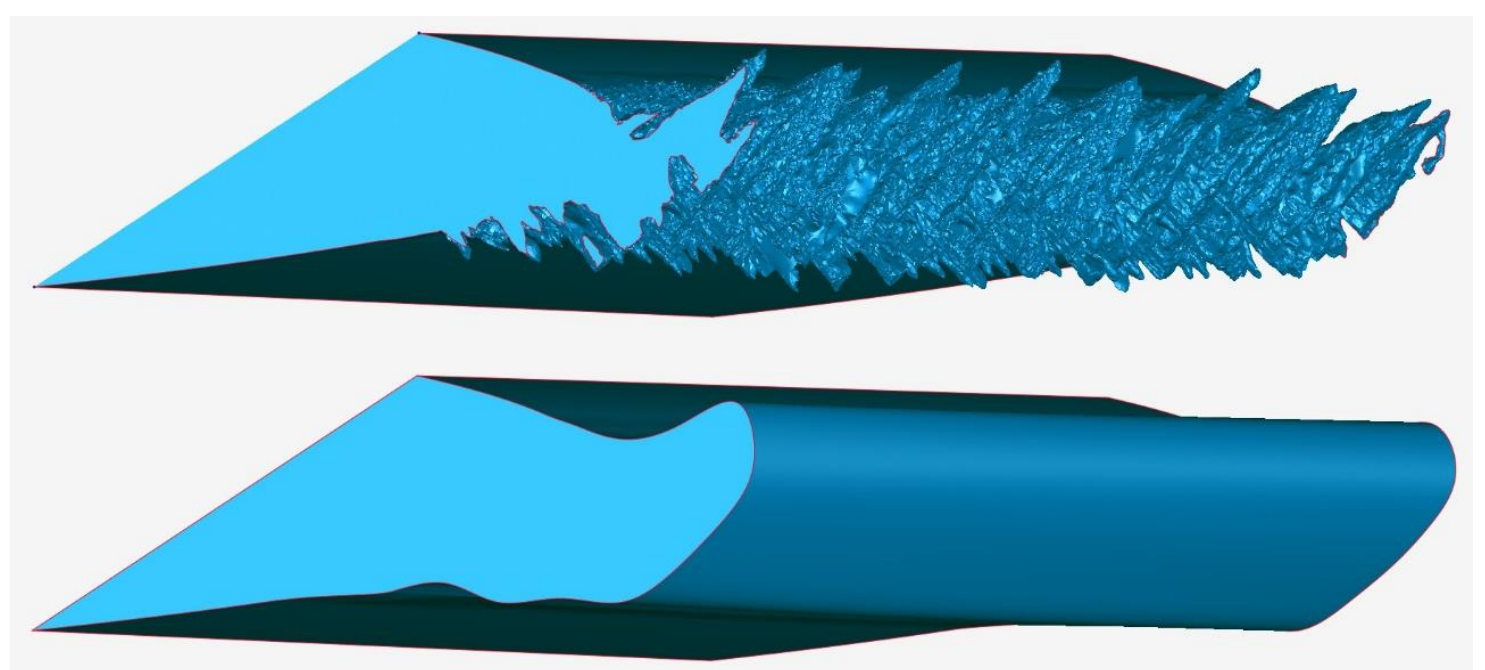

Figure 8. Comparison of high-fidelity artificial ice shape geometry (top) with the lower-fidelity, 3D smooth geometry (bottom).

Another, intermediate fidelity between the high-fidelity and 3D smooth ice shapes involves adding grit roughness to the $3 \mathrm{D}$ smooth ice shapes in order to simulate some ice roughness. The recommended roughness size of $3 \mathrm{~mm}$ for the full-scale aircraft comes from FAA Advisory Circular 25-25A. ${ }^{27}$ This corresponds to 46 grit size on the $13.3 \%$ model and 60 grit size on the $8.9 \%$ model. The grit is adhered using either epoxy or double-sided tape and is applied with an extremely dense coverage. During both the F1 and WSU test campaigns, three fidelities of the Maximum Scallop and the Streamwise/Rime ice shapes were tested. Only during the F1 test were all three fidelities of the WB33 ice shape available. Images of the three configurations installed 
on the F1 model are shown in Figs. 9-11. For the Maximum Scallop and WB33 ice shapes, the three dimensionality of the artificial ice shape is evident in the images. The ice shapes with grit roughness added to them illustrate that the roughness was applied over the entire ice shape and that it was applied with high density.

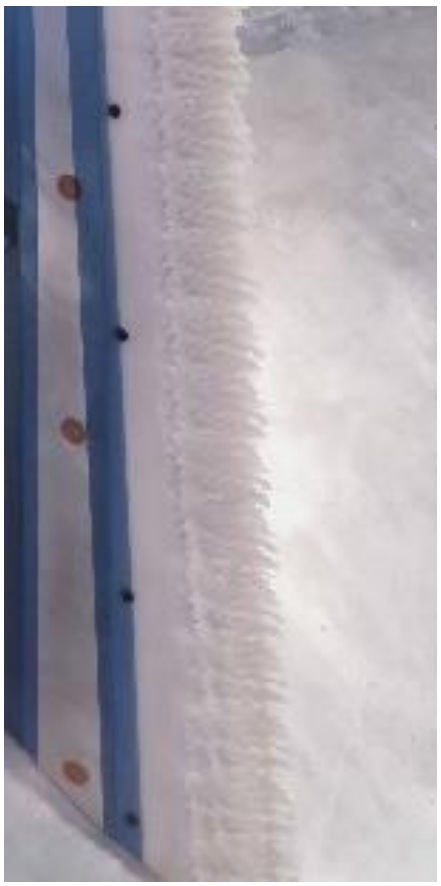

3D High Fidelity

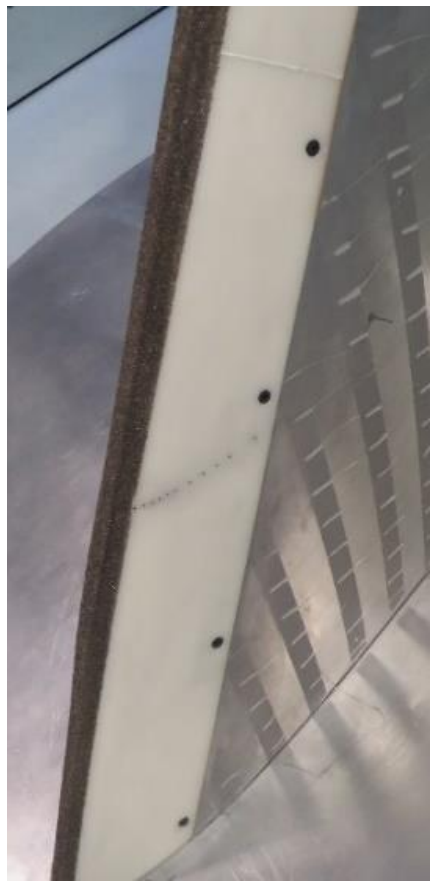

3D Smooth + Grit

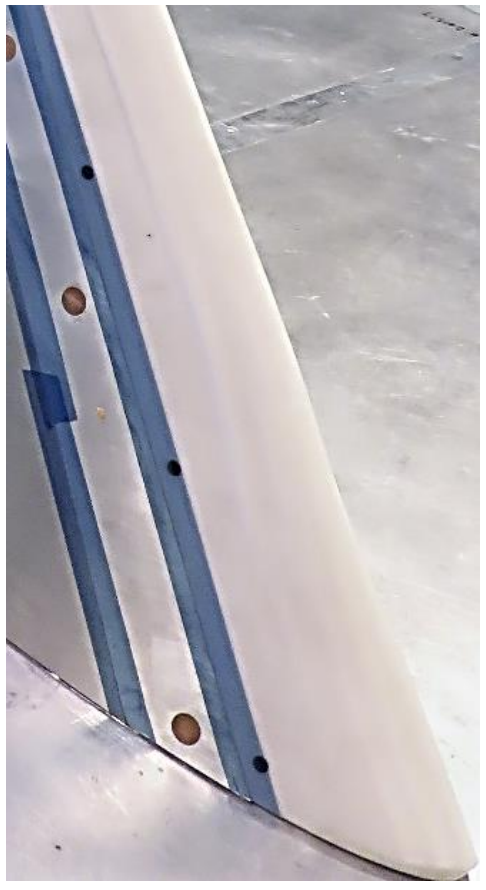

3D Smooth

Figure 9. Images showing three of the fidelity variations of the Max Scallop ice shape installed on the windtunnel model. 


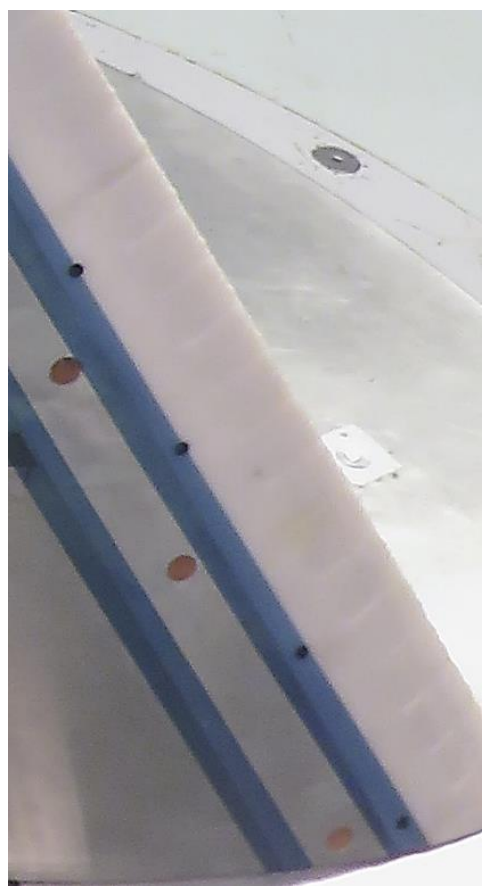

3D High Fidelity

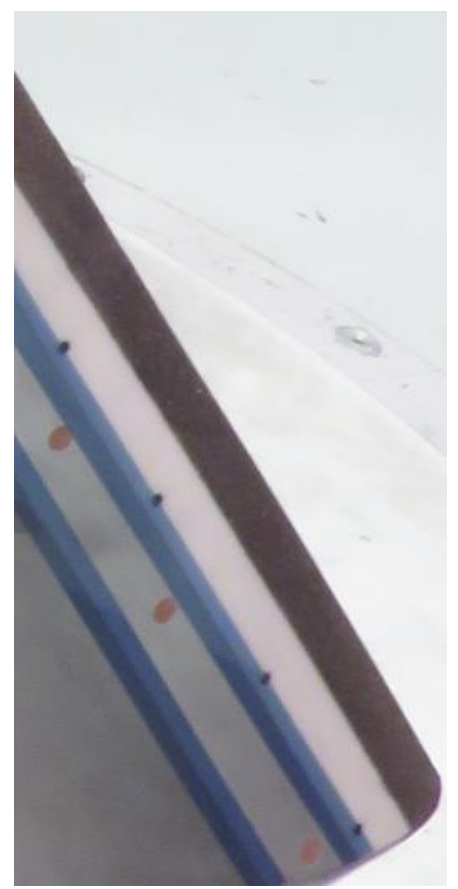

3D Smooth + Grit

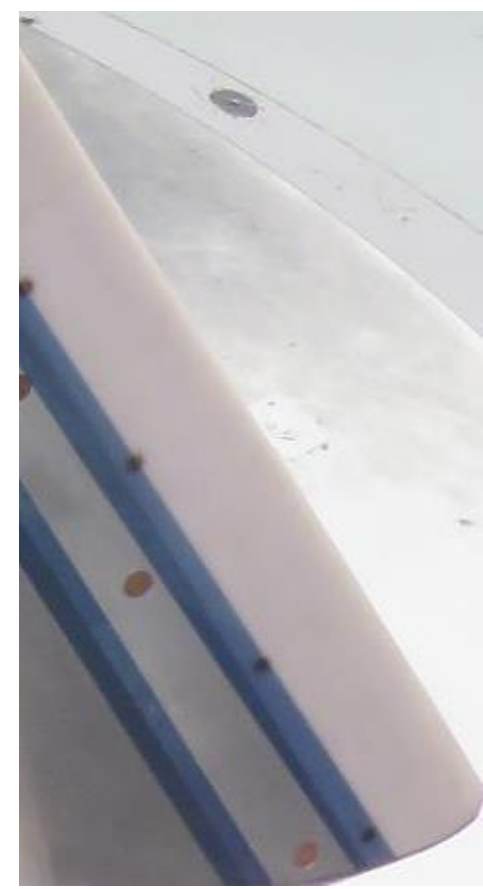

3D Smooth

Figure 10. Images showing three of the fidelity variations of the Streamwise/Rime ice shape installed on the wind-tunnel model.

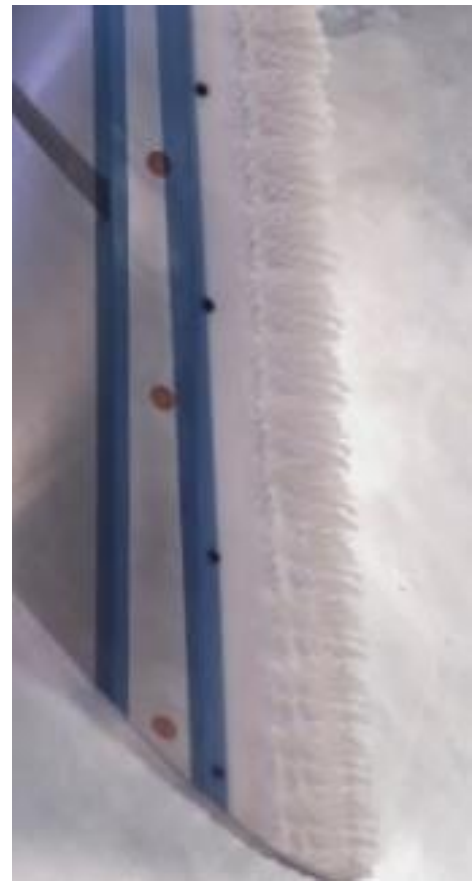

3D High Fidelity

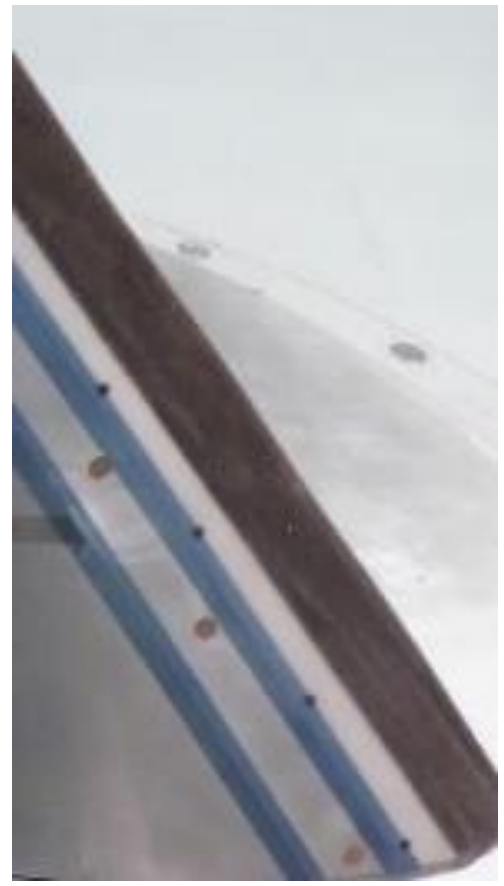

3D Smooth + Grit

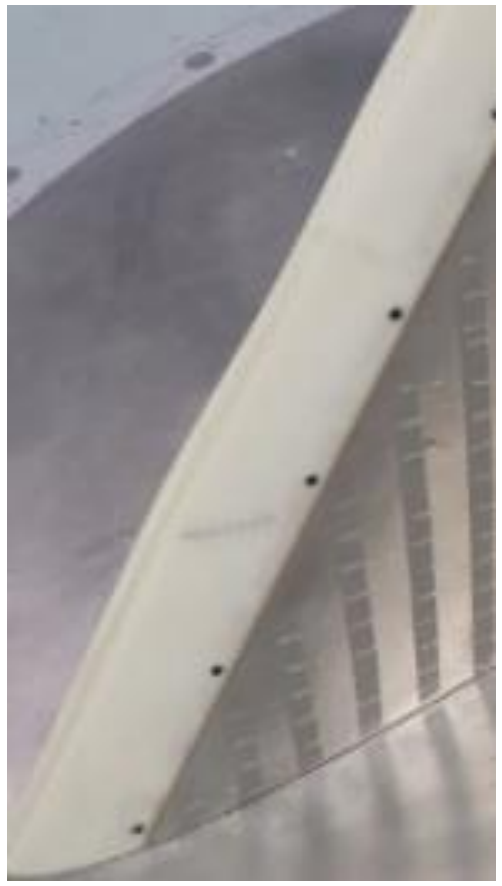

3D Smooth

Figure 11. Images showing three of the fidelity variations of the WB33 ice shape installed on the wind-tunnel model. 


\section{Results and Discussion}

The goal of this paper is to summarize the aerodynamic-performance differences between various fidelity representations of artificial ice shapes. The effects of Reynolds and Mach number on both the clean and iced wing are discussed in detail by Broeren et al. ${ }^{16}$ The most relevant conclusions from that paper involve the general trends observed in both the clean- and iced-wing performance parameters. For the clean wing, the lift-based parameters are substantially impacted by both Reynolds and Mach number effects. However, drag-based parameters do not show the same strong dependence even for the clean configuration. No Mach number effects were observed, and only weak Reynolds number effects were evident. For the iced configuration, the lift-based parameters showed little to no dependence on Reynolds number and Mach number for Mach numbers above 0.18 . The drag-based parameters indicated no Mach number influence and a small reduction in drag coefficients with increasing Reynolds number. Nearly all of the aerodynamic performance data presented here were selected from the highest Reynolds number case which is the closest to the flight Reynolds number. Additionally, Lee et al. ${ }^{17}$ discuss the details of the comparison between the two models tested in two different facilities. Since the majority of the data in this section are from the F1 test campaign with the 13.3\% CRM65 model, those data are not identified specifically as coming from that test. The data that came from the WSU test campaign using the $8.9 \%$ CRM65 model are specifically identified in plots or captions.

\section{A. Effect of 3D, High Fidelity Artificial Ice Shapes on Wing Performance}

As a baseline for subsequent comparisons, the aerodynamic performance data for the three artificial ice shapes discussed in Section II.C are presented in Fig. 12 with the clean wing plotted as a reference. This data set comes from the highest Reynolds number case $\left(R e=11.9 \times 10^{6}, M=\right.$ 0.23 ) and clearly identifies the substantial impact of the artificial ice shapes relative to the clean wing. The most significant impact on performance is readily observed to be the reduction in lift coefficient at high angles of attack and an increase in drag at all angles. The large, highly threedimensional ice shapes, Maximum Scallop and WB33, have a more substantial effect than the smaller, Streamwise/Rime ice shape. For all of the iced configurations, the lift coefficient diverges from the linear regime earlier than the clean configuration but continues to increase as the angle of attack increases. In fact, the maximum lift coefficient for the iced configurations occurs at a higher angle of attack than the angle at which the clean wing exhibits a clear stalling behavior 
identified by the sharp decrease in lift coefficient at slightly less than 16 deg. angle of attack. With a large number of cases for comparison, it is desirable to extract some parameters from these performance plots in order to compare Reynolds and Mach number effects as well as the fidelity variations. As described above using the example of maximum lift coefficient to define stalling angle, the standard metrics of $C_{L, \max }, C_{D, \min }$, and $\alpha_{\text {stall }}$ might not sufficiently capture the deleterious impact of the ice shapes, especially on lift.
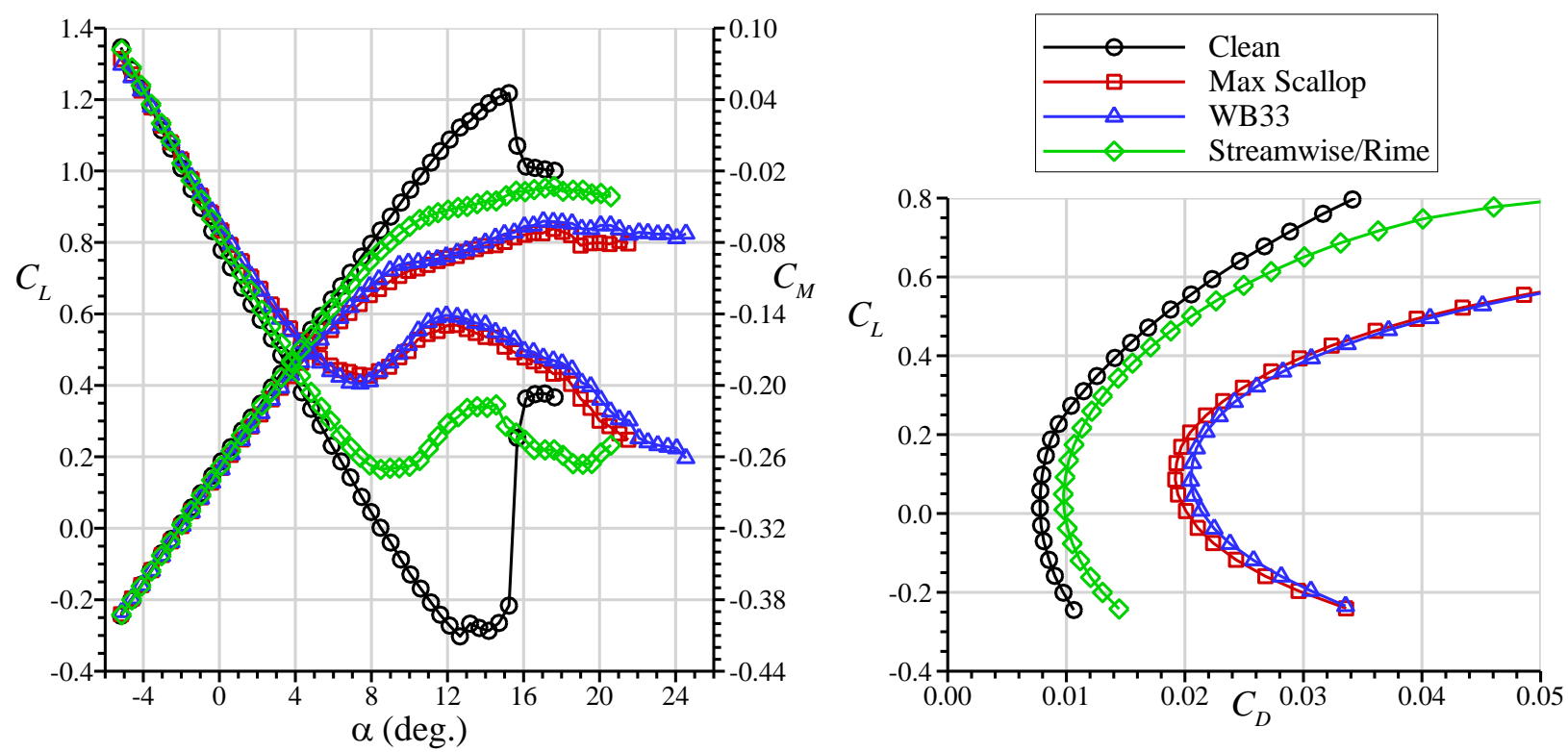

Figure 12. Aerodynamic performance comparison between the three high fidelity ice-shape conditions at $R e=11.9 \times 10^{6}, M=0.23$.

Additional performance parameters have been adapted for application to these swept-wing icing tests. Again, Broeren et al. ${ }^{16}$ provide further details of the application to this particular swept wing. In order to more completely capture the stall progression on the swept wing, a performance parameter called "usable" or "inflection" lift is defined based on past work by Furlong and McHugh. ${ }^{28}$ This lift coefficient is defined to be coincident with the first local minimum in the pitching moment coefficient calculated about the quarter-chord of the mean aerodynamic chord. As the flow separation progresses inboard from the wing tip, the pitching moment about the quarter-chord of the mean aerodynamic chord eventually begins to increase indicating a substantial flow separation. As the data in Fig. 12 (and subsequent figures) illustrate, the first local minimum in the pitching-moment coefficient nearly corresponds to the angle of attack where the lift coefficient diverges from the linear range. These lift parameters are specifically denoted as $C_{L \text {,use }}$ and $\alpha_{u s e}$. 
A useful additional parameter can also be extracted from the drag data. The minimum drag value is a convenient parameter for comparing the ice-shape fidelity variations since it occurs near zero lift, so the influence of induced drag is minimized. However, an aircraft does not operate at zero lift, so another point of comparison, at higher lift coefficient, is desirable. Lynch and Khodadoust ${ }^{29}$ suggest a process for determining this drag coefficient, and Broeren et al. ${ }^{16}$ explain the implementation for this particular swept wing. A lift coefficient equal to 0.6 was identified as the reference value for determining the drag coefficient, and this associated drag value is denoted as $C_{D, 0.6}$ to indicate that it is the drag coefficient when $C_{L}=0.6$. All of the aerodynamic performance data from the F1 tests were analyzed to determine these parameters, and selected cases from the WSU tests were evaluated as well.

\section{B. Effect of Ice Shape Fidelity on Maximum Scallop Ice Shape}

As described in Section II.C, three fidelities of the Maximum Scallop ice shape were available for comparison. Figure 13 illustrates the overall aerodynamic performance for the Maximum Scallop ice shape and the clean wing at the highest Reynolds number. The high-fidelity version has the most severe penalty in both lift and drag relative to the clean wing. When grit is added to the 3D Smooth ice shape the lift decreases and the drag increases but not nearly to the level of the high fidelity ice shape.
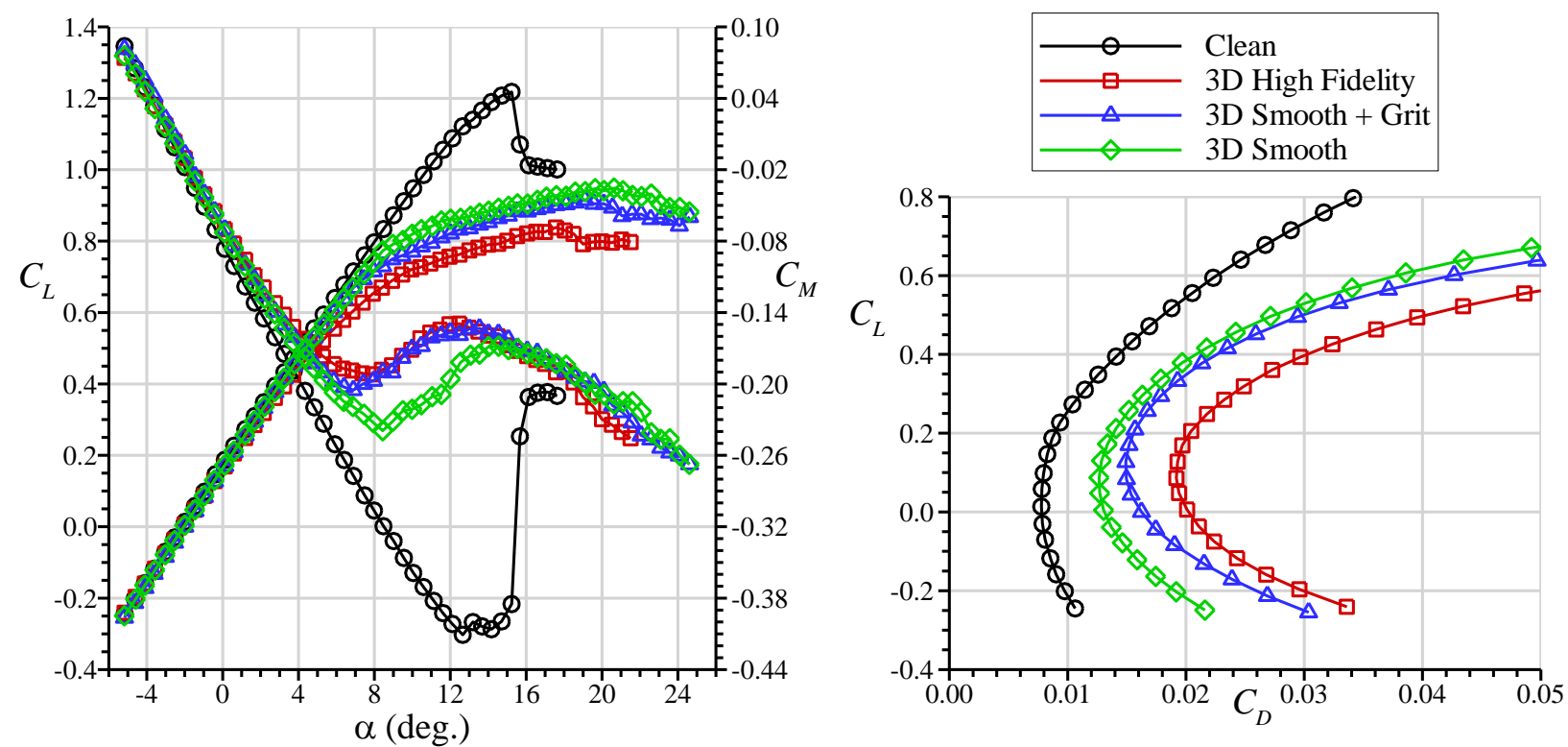

Figure 13. Aerodynamic performance comparison between the four fidelity representations of the Maximum Scallop ice shape at $R e=11.9 \times 10^{6}, M=0.23$. 
In order to make a more thorough comparison of these fidelity variations on the wing performance, the parameters described in the preceding section are tabulated in Table 3 for lift, Table 4 for angle of attack, and Table 5 for drag at the same Reynolds and Mach number conditions in from Fig. 13. In the tables, the differences in all of the parameters are calculated relative to the high fidelity ice shape. For the lift- and drag-based parameters, the percent different is also tabulated. These differences are calculated such that the high-fidelity value is subtracted from the low-fidelity value. An increase in lift coefficient from the high-fidelity value to the low-fidelity value results in a positive parameter. The percent difference is defined as that difference divided by the high-fidelity value such that sign or direction of change always matches between the change and percent change values. Both $C_{L, \max }$ and $C_{L, u s e}$ decrease from the clean wing in the anticipated order. For the three ice-shape fidelities, the three dimensionality drives the lift performance. The smoothest ice shape has the largest lift, followed by the grit roughness added to the smooth ice shape, and then the high-fidelity representation. Table 4 clearly illustrates the need for multiple parameters to completely understand the performance impact from all of these artificial ice shapes. The value of $\alpha_{\text {stall }}$ is higher for the high-fidelity ice shape than for the clean wing, and the $\alpha_{\text {stall }}$ and $\alpha_{\text {use }}$ values are in a different order based on the fidelity.

Table 3. Summary of Maximum Scallop Lift Performance Parameters for Various Fidelities at $\operatorname{Re}=11.9 \times 10^{6}, M=0.23$.

\begin{tabular}{|c|c|c|c|c|c|c|}
\hline & \multicolumn{3}{|c|}{$\overline{C_{L, \max }}$} & \multicolumn{3}{|c|}{$C_{L, \text { use }}$} \\
\hline Ice Shape Fidelity & $C_{L, \max }$ & $\begin{array}{l}\qquad \Delta C_{L, \max } \\
\text { Low Fidelity - } \\
\text { High Fidelity }\end{array}$ & $\begin{array}{l}\text { Percent } \Delta C_{L, \max } \\
\text { (Low Fidelity - } \\
\text { High Fidelity) } \\
\text { / High Fidelity }\end{array}$ & $C_{L, \text { use }}$ & $\begin{array}{c}\Delta C_{L, u s e} \\
\text { Low Fidelity - } \\
\text { High Fidelity }\end{array}$ & $\begin{array}{l}\text { Percent } \Delta C_{L, \text { use }} \\
\text { (Low Fidelity - } \\
\text { High Fidelity) } \\
\text { / High Fidelity }\end{array}$ \\
\hline Clean & 1.218 & - & - & 1.122 & - & - \\
\hline 3D High Fidelity & 0.838 & - & - & 0.652 & - & - \\
\hline 3D Smooth + Grit & 0.915 & 0.077 & $9.2 \%$ & 0.669 & 0.017 & $2.6 \%$ \\
\hline 3D Smooth & 0.947 & 0.109 & $13 \%$ & 0.773 & 0.120 & $19 \%$ \\
\hline
\end{tabular}

Table 4. Summary of Maximum Scallop Angle of Attack Performance Parameters for Various Fidelities at $\operatorname{Re}=11.9 \times 10^{6}, M=0.23$.

\begin{tabular}{|c|c|c|c|c|}
\hline & \multicolumn{2}{|r|}{$\alpha_{\text {stall }}$} & \multicolumn{2}{|r|}{$\alpha_{\text {use }}$} \\
\hline Ice Shape Fidelity & $\begin{array}{c}\alpha_{\text {stall }} \\
\text { (deg.) }\end{array}$ & $\begin{array}{c}\Delta \alpha_{\text {stall }} \\
\text { Low Fidelity - } \\
\text { High Fidelity } \\
\text { (deg.) }\end{array}$ & $\begin{array}{c}\alpha_{\text {use }} \\
\text { (deg.) }\end{array}$ & $\begin{array}{c}\Delta \alpha_{u s e} \\
\text { Low Fidelity - } \\
\text { High Fidelity } \\
\text { (deg.) }\end{array}$ \\
\hline Clean & 15.2 & - & 12.7 & - \\
\hline 3D High Fidelity & 17.6 & - & 7.9 & - \\
\hline 3D Smooth + Grit & 19.1 & 1.5 & 6.9 & -1.0 \\
\hline 3D Smooth & 19.6 & 2.1 & 8.4 & 0.5 \\
\hline
\end{tabular}


The data presented in Table 5 for the drag-based comparison parameters show the differences and percent differences similarly to the lift-based parameters. The negative values in the table indicate that the drag is reduced for the lower-fidelity ice shapes relative to the high-fidelity shape. The trends in drag performance impact are the same, based on fidelity, using either performance parameter. The magnitude of the drag values and associated differences are much higher for $C_{D, 0.6}$ compared with $C_{D \text {, min }}$, but the percentage effects are similar between the two parameters. Both parameters indicate that adding grit to the 3D smooth ice shape increases the drag penalty toward the high-fidelity representation, but that the 3D smooth + grit ice shapes still fall over $20 \%$ lower than the impact due to the high-fidelity ice shape. These results indicate that, for highly threedimensional ice formations like the Maximum Scallop ice shape, the smooth representations are not conservative approximations of the icing impact even when grit roughness is added to the ice shape.

Table 5. Summary of Maximum Scallop Drag Performance Parameters for Various Fidelities at $R e=11.9 \times 10^{6}, M=0.23$.

\begin{tabular}{|c|c|c|c|c|c|c|}
\hline & \multicolumn{3}{|c|}{$C_{D, \min }$} & \multicolumn{3}{|c|}{$C_{D, 0.6}$} \\
\hline Ice Shape Fidelity & $C_{D, \min }$ & $\begin{array}{c}\Delta C_{D, \min } \\
\text { Low Fidelity - } \\
\text { High Fidelity }\end{array}$ & $\begin{array}{l}\text { Percent } \Delta C_{D, \min } \\
\text { (Low Fidelity - } \\
\text { High Fidelity) } \\
\text { / High Fidelity }\end{array}$ & $C_{D, 0.6}$ & $\begin{array}{l}\qquad \Delta C_{D, 0.6} \\
\text { Low Fidelity - } \\
\text { High Fidelity }\end{array}$ & $\begin{array}{l}\text { Percent } \Delta C_{D, 0.6} \\
\text { (Low Fidelity - } \\
\text { High Fidelity) } \\
\text { / High Fidelity }\end{array}$ \\
\hline Clean & 0.0078 & - & - & 0.0226 & - & - \\
\hline 3D High Fidelity & 0.0192 & - & - & 0.0584 & - & - \\
\hline 3D Smooth + Grit & 0.0149 & -0.0043 & $-22 \%$ & 0.0425 & -0.0159 & $-27 \%$ \\
\hline 3D Smooth & 0.0127 & -0.0065 & $-34 \%$ & 0.0378 & -0.0206 & $-35 \%$ \\
\hline
\end{tabular}

The surface pressures measured on the wing can be linearly interpolated to create pressure contour plots as shown in Fig. 14, and these plots can reveal general trends in the flowfield. The outline of the wing is shown in each contour plot, and the small circles represent the individual pressure taps that were utilized to create the image. The angles of attack selected for the plots show the pressure distribution as the wing passes through the point of maximum usable lift as defined previously from approximately $\alpha=7.4 \mathrm{deg}$. to $9.5 \mathrm{deg}$. for the highest Reynolds number case $R e=11.9 \times 10^{6}, M=0.23$. For both configurations, the pressure distribution can be observed to clearly change as the wing passes $\alpha_{\text {use }}$. For the high-fidelity configuration $\alpha_{\text {use }}=7.9 \mathrm{deg}$., and for the 3D smooth ice shape, $\alpha_{u s e}=8.4 \mathrm{deg}$. The pressure distribution prior to $\alpha_{u s e}$ shows a lowpressure region along the leading edge of the wing for most of the span. 

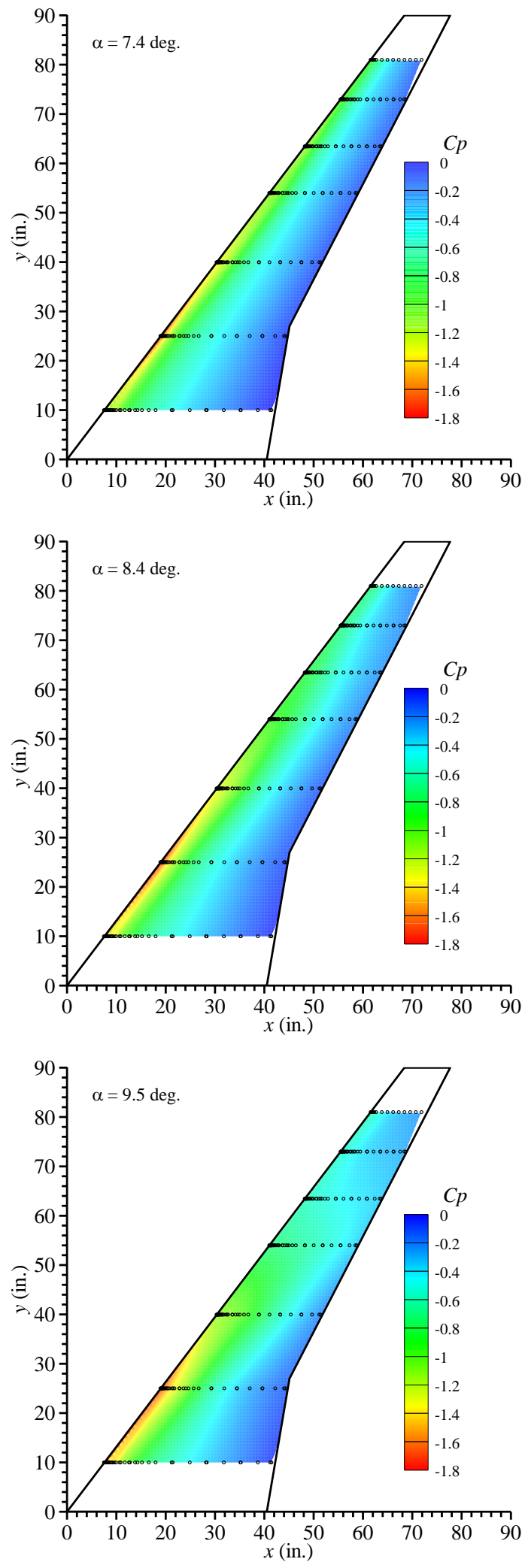

3D High Fidelity
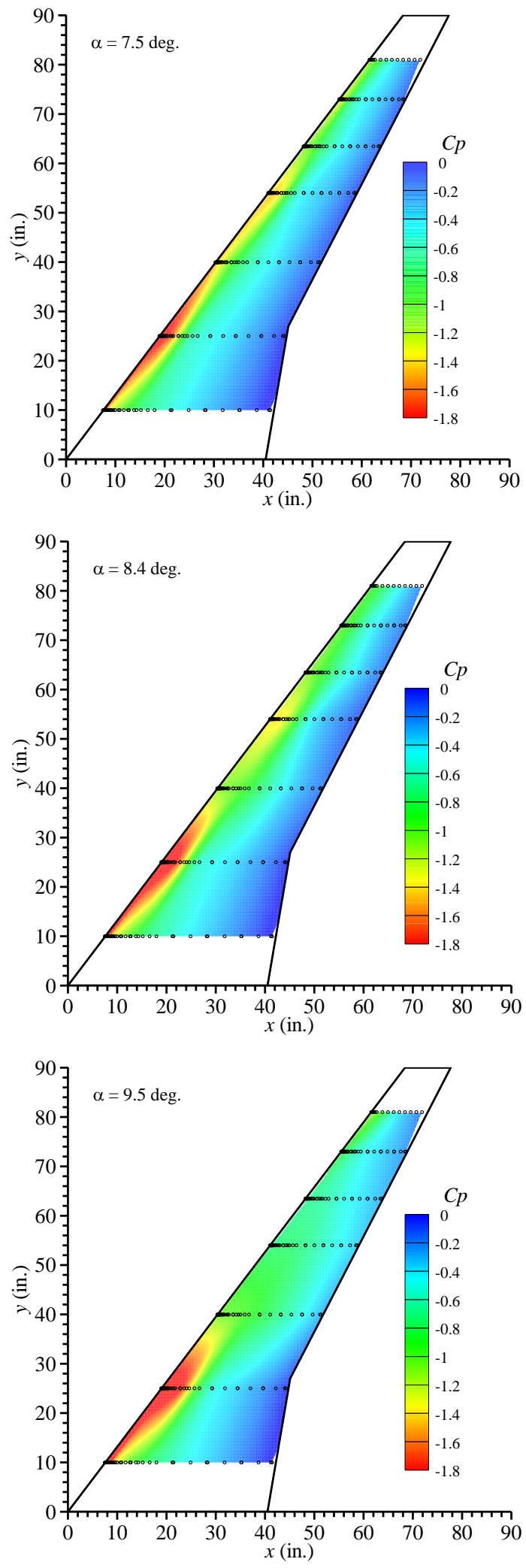

3D Smooth

Figure 14. Contours of upper-surface pressure for 3D high-fidelity and 3D smooth representations of the Maximum Scallop ice shape for $\alpha=7.4,8.4$ and $9.5 \mathrm{deg}$ at $R e=11.9 \times 10^{6}$ and $M=0.23$. 
After $\alpha_{u s e}$, the low-pressure region is concentrated on the inboard portion of the model which clearly illustrates why the slope of the pitching-moment coefficient calculated about the quarterchord of the mean aerodynamic chord changes with angle of attack. These images illustrate the general flowfield differences on the wing prior to and after $\alpha_{\text {use }}$. For all three angles of attack shown, the low-pressure region is larger for the $3 \mathrm{D}$ smooth ice shape which is consistent with the larger lift coefficient values in this angle of attack range for the smooth ice shape relative to the high-fidelity ice shape. These results further illustrate that, although the lift curves are not drastically different between the iced configurations relative to the clean model, the pressure distributions are different indicating different flow characteristics between the different fidelity representations of the ice shapes. The lower-fidelity representations may or may not be accurately representing the flowfield created by the high-fidelity ice shape. Additional investigation of these pressure contours at additional angles of attack might reveal more information regarding the different flowfields generated downstream of these artificial ice shapes and how those flowfields affect the progression of flow separation and stall. However, those studies will be the subject of future work. Sandu et al. ${ }^{18}$ investigate some of these flowfield differences in greater details for the Maximum Scallop ice shape.

\section{Effect of Ice Shape Fidelity on WB33 Ice Shape}

The aerodynamic performance data are shown for the three fidelities of the WB33 ice shape plus the clean configuration in Fig. 15. The relative differences in lift and drag coefficients between the various fidelities are similar to those shown for the Maximum Scallop ice shape. The same lift and drag performance parameters have been applied to these data sets in order to make more precise comparisons. Tables 6,7 , and 8 contains the lift-based parameters, stall angles of attack, and the drag-based parameters, respectively. The lift coefficients track in the expected way with fidelity, and associated angles of attack generally follow the same trends. The 3D smooth + grit ice shape nearly results in the same lift coefficient as the high-fidelity ice shape. Even the 3D smooth ice shape only has a lift coefficient of less than $10 \%$ higher than the high-fidelity case. Similarly to the Maximum Scallop comparison, the different fidelities have little impact on $\alpha_{\text {use }}$ where the values of $\alpha_{\text {stall }}$ are all greater than the $\alpha_{\text {stall }}$ value for the clean wing and highest for the 3D smooth fidelity. The drag coefficients also follow the same pattern expected from the Maximum Scallop fidelity data, since the ice shapes have similar size and three-dimensionality. 
The magnitude of the drag impact on this WB33 ice shape relative to fidelity is fairly similar to the Maximum Scallop ice shape as well, and this ice shape also indicates that the smooth representation, even with grit, is not conservative with regard to the impact on aerodynamic performance relative to the high-fidelity ice shape. Generalizing for the Maximum Scallop and WB33 ice shapes, the 3D smooth fidelity captures approximately $30 \%$ less drag than the highfidelity ice shape, and the 3D smooth + grit fidelity captures $25 \%$ less drag.
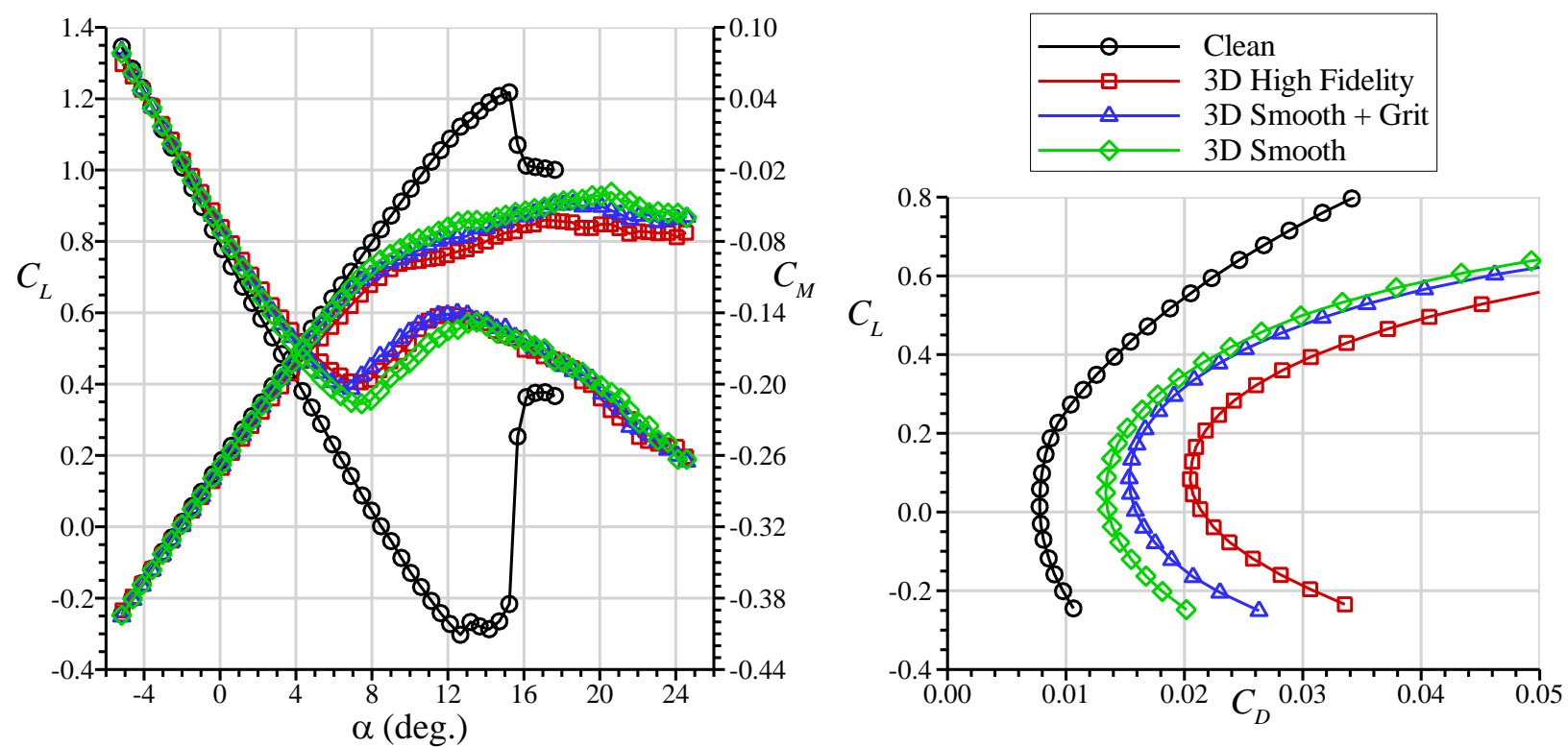

Figure 15. Aerodynamic performance comparison between the three fidelity representations of the WB33 ice shape at $R e=11.9 \times 10^{6}, M=0.23$.

Table 6. Summary of WB33 Lift Performance Parameters for Various Fidelities at $R e=11.9 \times 10^{6}, M=0.23$.

\begin{tabular}{|c|c|c|c|c|c|c|}
\hline & \multicolumn{3}{|c|}{$C_{L, \max }$} & \multicolumn{3}{|c|}{$C_{L, \text { use }}$} \\
\hline Ice Shape Fidelity & $C_{L, \max }$ & $\begin{array}{c}\Delta C_{L, \max } \\
\text { Low Fidelity - } \\
\text { High Fidelity }\end{array}$ & $\begin{array}{l}\text { Percent } \Delta C_{L, \max } \\
\text { (Low Fidelity - } \\
\text { High Fidelity) } \\
\text { / High Fidelity }\end{array}$ & $C_{L, u s e}$ & $\begin{array}{c}\Delta C_{L, u s e} \\
\text { Low Fidelity - } \\
\text { High Fidelity }\end{array}$ & $\begin{array}{l}\text { Percent } \Delta C_{L, \text { use }} \\
\text { (Low Fidelity - } \\
\text { High Fidelity) } \\
\text { / High Fidelity }\end{array}$ \\
\hline Clean & 1.218 & - & - & 1.122 & - & - \\
\hline 3D High Fidelity & 0.860 & - & - & 0.650 & - & - \\
\hline 3D Smooth + Grit & 0.906 & 0.046 & $5.4 \%$ & 0.670 & 0.020 & $3.0 \%$ \\
\hline 3D Smooth & 0.937 & 0.077 & $9.0 \%$ & 0.705 & 0.055 & $8.4 \%$ \\
\hline
\end{tabular}


Table 7. Summary of WB33 Angle of Attack Performance Parameters for Various Fidelities at $R e=11.9 \times 10^{6}, M=0.23$.

\begin{tabular}{c|cc|cc}
\hline \hline & \multicolumn{2}{|c|}{$\alpha_{\text {stall }}$} & \multicolumn{2}{c}{$\alpha_{\text {use }}$} \\
\hline & \multicolumn{3}{|c|}{$\begin{array}{c}\Delta \alpha_{\text {stall }} \\
\text { Low Fidelity - }\end{array}$} & \multicolumn{2}{c}{$\begin{array}{c}\Delta \alpha_{\text {use }} \\
\text { Low Fidelity - } \\
\text { High Fidelity }\end{array}$} & $\begin{array}{c}\alpha_{\text {use }} \\
\text { High Fidelity }\end{array}$ \\
& $\alpha_{\text {stall }}$ & $\begin{array}{c}\text { Heg.) } \\
\text { (deg.) }\end{array}$ & (deg.) \\
\hline Clean & 15.2 & - & 12.7 & - \\
3D High Fidelity & 17.0 & - & 7.4 & - \\
3D Smooth + Grit & 18.6 & 3.6 & 6.9 & -0.5 \\
3D Smooth & 20.6 & 1.6 & 7.5 & 0.1 \\
\hline \hline
\end{tabular}

Table 8. Summary of WB33 Drag Performance Parameters for Various Fidelities at $R e=11.9 \times 10^{6}, M=0.23$.

\begin{tabular}{|c|c|c|c|c|c|c|}
\hline & \multicolumn{3}{|c|}{$C_{D, \min }$} & \multicolumn{3}{|c|}{$C_{D, 0.6}$} \\
\hline Ice Shape Fidelity & $C_{D, \min }$ & $\begin{array}{c}\Delta C_{D, \min } \\
\text { Low Fidelity - } \\
\text { High Fidelity }\end{array}$ & $\begin{array}{l}\text { Percent } \Delta C_{D, \min } \\
\text { (Low Fidelity - } \\
\text { High Fidelity) } \\
\text { / High Fidelity }\end{array}$ & $C_{D, 0.6}$ & $\begin{array}{c}\Delta C_{D, 0.6} \\
\text { Low Fidelity - } \\
\text { High Fidelity }\end{array}$ & $\begin{array}{l}\text { Percent } \Delta C_{D, 0.6} \\
\text { (Low Fidelity } \\
\text { High Fidelity) } \\
\text { / High Fidelity }\end{array}$ \\
\hline Clean & 0.0078 & - & - & 0.0226 & - & - \\
\hline 3D High Fidelity & 0.0205 & - & - & 0.0585 & - & - \\
\hline 3D Smooth + Grit & 0.0153 & -0.0052 & $-25 \%$ & 0.0457 & -0.0128 & $-22 \%$ \\
\hline 3D Smooth & 0.0134 & -0.0071 & $-35 \%$ & 0.0424 & -0.0161 & $-27 \%$ \\
\hline
\end{tabular}

\section{Effect of Ice Shape Fidelity on Streamwise/Rime Ice Shape}

Figure 16 illustrates the aerodynamic performance differences between the fidelities of the Streamwise/Rime ice shape. As discussed before, this ice shape has less spanwise three dimensionality relative to the other two ice shapes that have been described. As such, the differences between the high-fidelity and lower-fidelity representations are small. In fact, the performance of the 3D smooth + grit configuration actually reduces $C_{L, \max }$ below the value measured with the high fidelity configuration as Table 9 indicates with the negative value in that column. The value of $C_{L, u s e}$ is higher for the 3D smooth + grit configuration compared to the high fidelity, but in this case, the pitching-moment coefficient shows a somewhat ambiguous minimum making it difficult to precisely identify $\alpha_{u s e}$ which could lead to determining a higher $C_{L, u s e}$ value. As Fig. 16 shows, the slope of the pitching-moment curve clearly changes several degrees before the local minimum is observed. If that lower angle of attack point was identified as $\alpha_{\text {use }}$, then the $C_{L, u s e}$ would be nearly identical to the high-fidelity value. The magnitude of the impact on drag is smaller for this dimensionally-smaller ice shape relative to the two previously discussed ice shapes. The stall angles are documented in Table 10. For the other two ice shapes, the stall angle 
(both $\alpha_{\text {stall }}$ and $\alpha_{\text {use }}$ ) increased with reduced fidelity in the ice shape. The value of $\alpha_{\text {stall }}$ is reduced, relative to the high-fidelity ice shape, with the addition of grit to the 3D smooth ice shape.
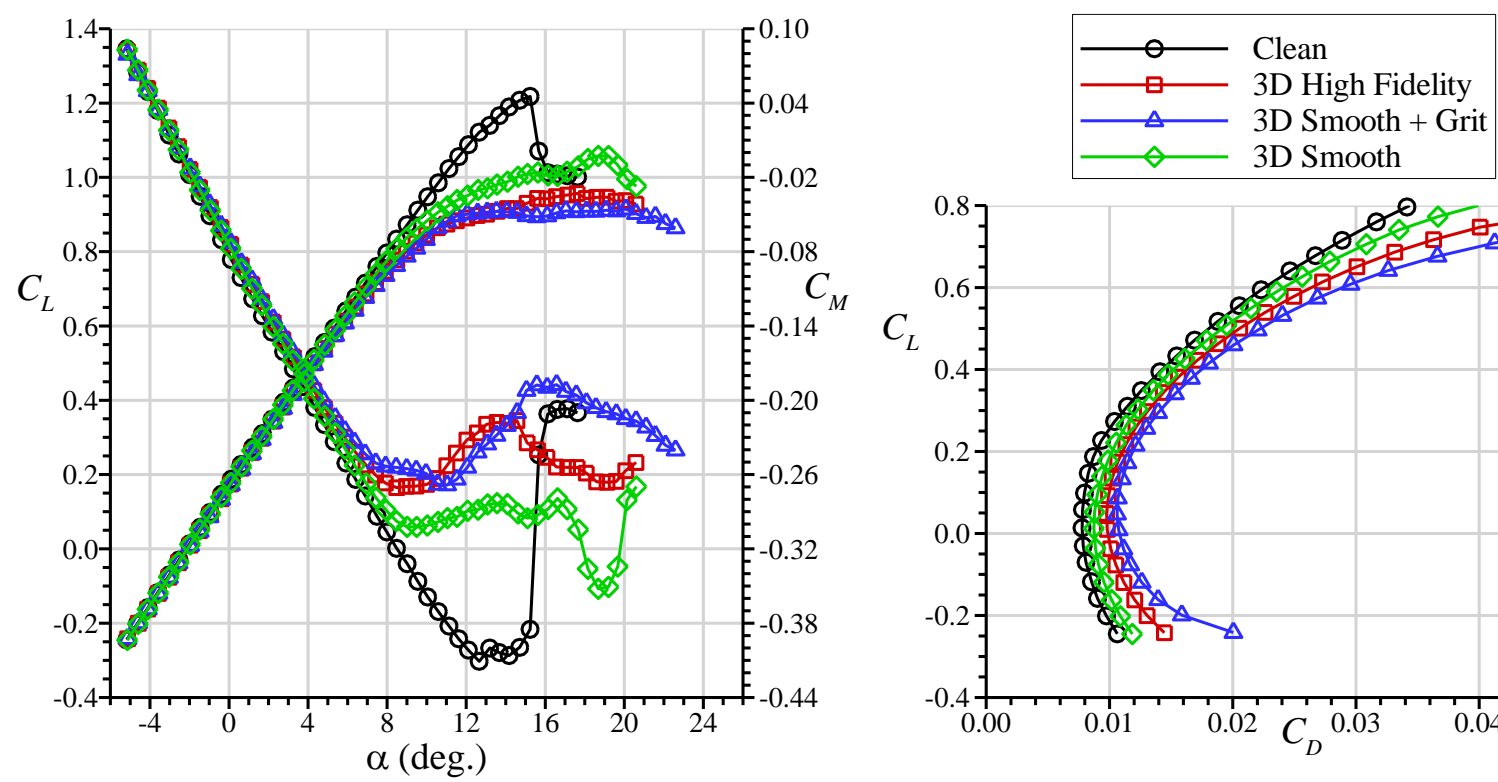

Figure 16. Aerodynamic performance comparison between the three fidelity representations of the Streamwise/Rime ice shape at $R e=11.9 \times 10^{6}, M=0.23$.

Table 9. Summary of Streamwise/Rime Lift Performance Parameters for Various Fidelities at $\operatorname{Re}=11.9 \times 10^{6}, M=0.23$.

\begin{tabular}{|c|c|c|c|c|c|c|}
\hline & \multicolumn{3}{|c|}{$C_{L, \max }$} & \multicolumn{3}{|c|}{$C_{L, \text { use }}$} \\
\hline Ice Shape Fidelity & $C_{L, \max }$ & $\begin{array}{c}\Delta C_{L, \max } \\
\text { Low Fidelity - } \\
\text { High Fidelity }\end{array}$ & $\begin{array}{l}\text { Percent } \Delta C_{L, \max } \\
\text { (Low Fidelity - } \\
\text { High Fidelity) } \\
\text { / High Fidelity }\end{array}$ & $C_{L, u s e}$ & $\begin{array}{c}\Delta C_{L, \text { use }} \\
\text { Low Fidelity - } \\
\text { High Fidelity }\end{array}$ & $\begin{array}{l}\text { Percent } \Delta C_{L, \text { use }} \\
\text { (Low Fidelity - } \\
\text { High Fidelity) } \\
\text { / High Fidelity }\end{array}$ \\
\hline Clean & 1.218 & - & - & 1.122 & - & - \\
\hline 3D High Fidelity & 0.957 & - & 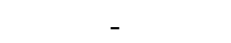 & 0.777 & - & . \\
\hline 3D Smooth + Grit & 0.908 & -0.049 & $-5.1 \%$ & 0.882 & 0.104 & $13.4 \%$ \\
\hline 3D Smooth & 1.058 & 0.101 & $10.6 \%$ & 0.861 & 0.083 & $10.7 \%$ \\
\hline
\end{tabular}

Table 10. Summary of Streamwise/Rime Angle of Attack Performance Parameters for Various Fidelities at $R e=11.9 \times 10^{6}, M=0.23$.

\begin{tabular}{|c|c|c|c|c|}
\hline & \multicolumn{2}{|r|}{$\alpha_{\text {stall }}$} & \multicolumn{2}{|r|}{$\alpha_{\text {use }}$} \\
\hline Ice Shape Fidelity & $\begin{array}{c}\alpha_{\text {stall }} \\
\text { (deg.) }\end{array}$ & $\begin{array}{c}\Delta \alpha_{\text {stall }} \\
\text { Low Fidelity - } \\
\text { High Fidelity } \\
\text { (deg.) }\end{array}$ & $\begin{array}{c}\alpha_{\text {use }} \\
\text { (deg.) }\end{array}$ & $\begin{array}{c}\Delta \alpha_{u s e} \\
\text { Low Fidelity - } \\
\text { High Fidelity } \\
\text { (deg.) }\end{array}$ \\
\hline Clean & 15.2 & - & 12.7 & - \\
\hline 3D High Fidelity & 17.6 & - & 8.5 & - \\
\hline 3D Smooth + Grit & 13.5 & -4.1 & 11.0 & 2.5 \\
\hline 3D Smooth & 18.7 & 1.1 & 9.5 & 1.0 \\
\hline
\end{tabular}


Furthermore, the addition of the grit roughness increases the drag beyond the high-fidelity value. Table 11 summarizes the drag performance parameters for the Streamwise/Rime ice shape. These relatively large drag values associated with the 3D smooth + grit configurations are identified by the positive values in the $C_{D}$ columns. The grit configuration increases both $C_{D, \min }$ and $C_{D, 0.6}$ by nearly $10 \%$ beyond the high-fidelity ice shape. Interestingly, although the $3 \mathrm{D}$ smooth + grit ice shape causes a drag increase beyond the high-fidelity ice shape, the 3D smooth ice shape still results in a reduced drag impact relative to the high fidelity ice shape. Similar to the Maximum Scallop and the WB33 ice shapes, the 3D smooth Streamwise/Rime ice shape captures less of the $C_{D, \min }$ value relative to high fidelity. In this case, the value is approximately $10 \%$ less compared to $25 \%$ and $34 \%$ for the WB33 and Maximum Scallop cases, respectively. Even though the threedimensional features of the Streamwise/Rime ice shape are smaller, they must still have an impact on the flowfield that is not accurately captured with either the 3D smooth or the 3D smooth + grit fidelities.

Table 11. Summary of Streamwise/Rime Drag Performance Parameters for Various Fidelities at $R e=11.9 \times 10^{6}, M=0.23$.

\begin{tabular}{|c|c|c|c|c|c|c|}
\hline \multirow[b]{2}{*}{ Ice Shape Fidelity } & \multicolumn{3}{|c|}{$C_{D, \min }$} & \multicolumn{3}{|c|}{$\overline{C_{D, 0.6}}$} \\
\hline & $C_{D, \min }$ & $\begin{array}{l}\qquad \Delta C_{D, \min } \\
\text { Low Fidelity - } \\
\text { High Fidelity }\end{array}$ & $\begin{array}{l}\text { Percent } \Delta C_{D, \min } \\
\text { (Low Fidelity - } \\
\text { High Fidelity) } \\
\text { / High Fidelity }\end{array}$ & $C_{D, 0.6}$ & $\begin{array}{c}\Delta C_{D, 0.6} \\
\text { Low Fidelity - } \\
\text { High Fidelity }\end{array}$ & $\begin{array}{l}\text { Percent } \Delta C_{D, 0.6} \\
\text { (Low Fidelity - } \\
\text { High Fidelity) } \\
\text { / High Fidelity }\end{array}$ \\
\hline Clean & 0.0078 & - & - & 0.0226 & - & - \\
\hline 3D High Fidelity & 0.0098 & - & - & 0.0264 & - & - \\
\hline 3D Smooth + Grit & 0.0106 & 0.0008 & $8.8 \%$ & 0.0289 & 0.0026 & $9.7 \%$ \\
\hline 3D Smooth & 0.0087 & -0.0011 & $-10.5 \%$ & 0.0241 & -0.0023 & $-8.6 \%$ \\
\hline
\end{tabular}

\section{E. Effect of Ice Shape Fidelity at Smaller Scale and Lower Reynolds Number}

The same three ice shapes that have been discussed in the previous three sections were also tested in the WSU facility. Some of the same fidelity configurations were tested although the configuration test matrix does not exactly overlap with those ice shapes tested in the F1 facility. Camello et al. ${ }^{14}$ discuss the impact of the various fidelities, and Lum et al. ${ }^{15}$ and Sandhu et al. ${ }^{18}$ have investigated the flowfields downstream of the ice shapes in more detail for the data collected at WSU. However, when Camello et al. ${ }^{14}$ published their work, the pitching-moment coefficient was calculated about a different reference location, and a different angle of attack correction was applied. The WSU aerodynamic coefficient data are plotted here with the pitching-moment referenced to the quarter-chord of the mean aerodynamic chord and the proper angle of attack 
correction applied. Figures 17, 18, and 19 show the performance data for the Maximum Scallop, WB33, and Streamwise/Rime ice shapes, respectively for wind tunnel conditions $R e=2.4 \times 10^{6}, M$ $=0.26$. This Reynolds and Mach number combination represents the highest Reynolds number possible in the WSU facility which is approximately a factor of five smaller than the maximum Reynolds number tested in the F1 facility. The Mach number is similar for the WSU data presented and the majority of the data presented from the F1 facility.
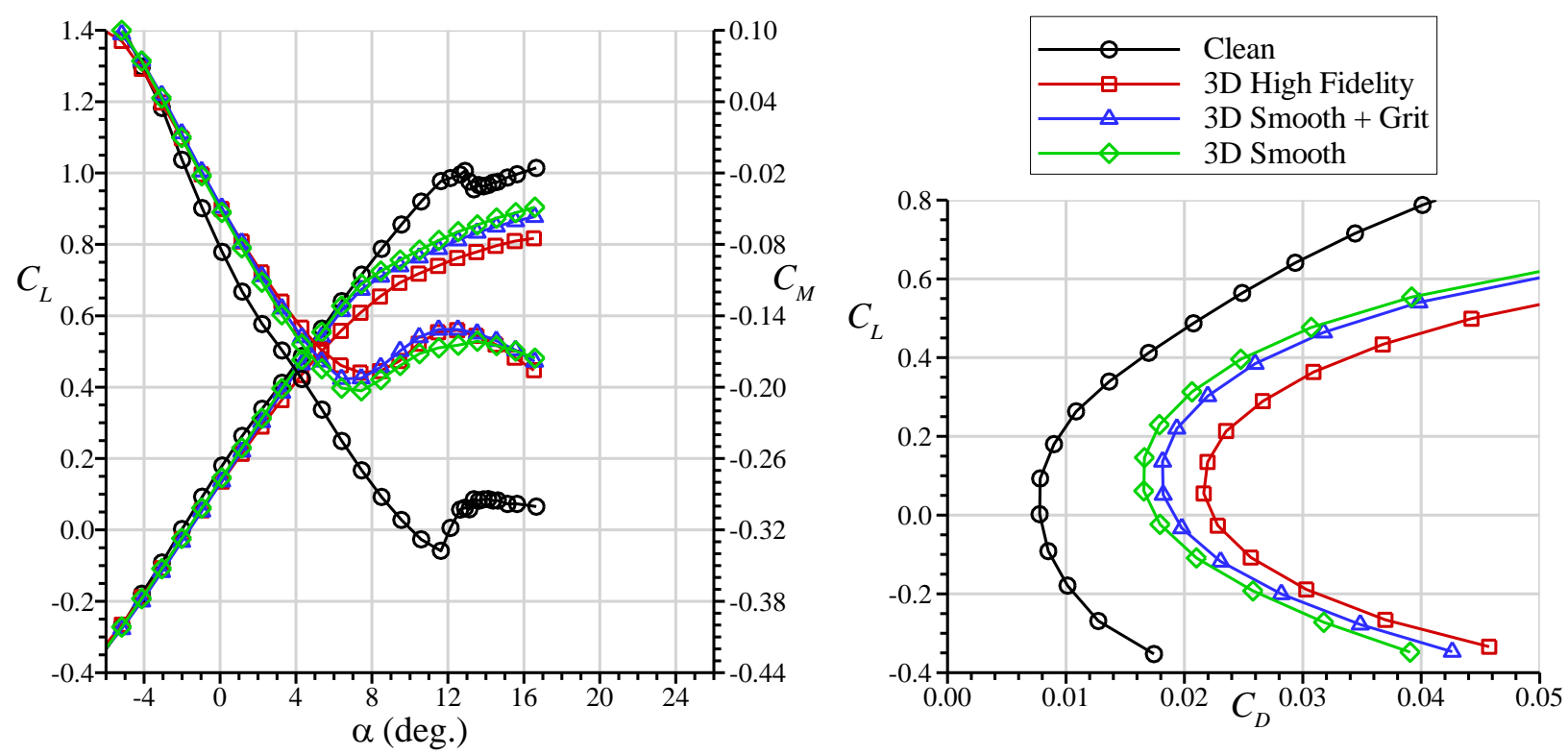

Figure 17. WSU Aerodynamic performance comparison between the three fidelity representations of the Maximum Scallop ice shape at $R e=2.4 \times 10^{6}, M=0.26$.

Similarly to the F1 data presented in the previous sections, the lift- and drag-based parameters were extracted from these data sets and summarized below. Due to differences in the way the data were collected, some of the same parameters are not available. In Table 12, only the usable lift coefficients are included. As Fig. 17 shows, the ice shapes did not reach an absolute maximum in lift coefficient, so it could not be included in the table. The usable lift coefficient values from WSU shown in the table agree well with the data from the F1 facility. The percent differences in $C_{L, \text { use }}$ are slightly smaller at WSU scale relative to the F1 scale. The pitching moment calculated about the quarter-chord of the mean aerodynamic chord shows a clear local minimum, so those usable lift values and associated angles of attack are tabulated. Table 13 contains the angles of attack. The angle of attack associated with the maximum usable lift 
coefficient agree extremely well between the F1 tests and those performed at WSU. The values agree within half a degree or less for both fidelity representations of the ice shapes.

Table 12. Summary of Maximum Scallop Lift Performance Parameters for Various Fidelities at WSU scale at $R e=2.4 \times 10^{6}, M=0.26$.

\begin{tabular}{|c|c|c|c|}
\hline \multirow[b]{2}{*}{ Ice Shape Fidelity } & \multicolumn{3}{|c|}{$C_{L, \text { use }}$} \\
\hline & $C_{L, \text { use }}$ & $\begin{array}{c}\Delta C_{L, u s e} \\
\text { Low Fidelity - } \\
\text { High Fidelity }\end{array}$ & $\begin{array}{l}\text { Percent } \Delta C_{L, \text { use }} \\
\text { (Low Fidelity - } \\
\text { High Fidelity) } \\
\text { / High Fidelity }\end{array}$ \\
\hline Clean & 0.977 & - & - \\
\hline 3D High Fidelity & 0.608 & 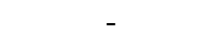 & - \\
\hline 3D Smooth + Grit & 0.613 & 0.005 & $0.9 \%$ \\
\hline 3D Smooth & 0.689 & 0.081 & $13.3 \%$ \\
\hline
\end{tabular}

Table 13. Summary of Maximum Scallop Angle of Attack Performance Parameters for Various Fidelities at WSU scale at $R e=2.4 \times 10^{6}, M=0.26$.

\begin{tabular}{c|cc}
\hline \hline & \multicolumn{2}{|c}{$\alpha_{\text {use }}$} \\
\hline & \multicolumn{3}{|c}{$\begin{array}{c}\Delta \alpha_{\text {use }} \\
\text { Low Fidelity - }\end{array}$} \\
& $\begin{array}{c}\alpha_{\text {use }} \\
\text { High Fidelity }\end{array}$ \\
Ice Shape Fidelity & (deg.) & (deg.) \\
\hline Clean & 11.6 & - \\
3D High Fidelity & 7.4 & - \\
3D Smooth + Grit & 6.4 & -1.0 \\
3D Smooth & 7.4 & 0.0 \\
\hline \hline
\end{tabular}

The drag-based performance parameters could all be defined for these tests, and the data are shown in Table 14. The trends of the impact of fidelity on the drag performance are the same between the two tests at different scales. However, the changes and percent changes in both drag parameters are smaller for the WSU tests compared to the F1 tests. Figure 18 shows the performance impact of the high-fidelity WB33 ice shape on the wing. Only that fidelity representation was available, so the differences in the performance parameters are not tabulated. Figure 19 contains the performance data from the Streamwise/Rime ice shape where three different fidelities were tested.

Table 14. Summary of Maximum Scallop Drag Performance Parameters for Various Fidelities at WSU scale at $R e=2.4 \times 10^{6}, M=0.26$.

\begin{tabular}{|c|c|c|c|c|c|c|}
\hline & \multicolumn{3}{|c|}{$C_{D, \min }$} & \multicolumn{3}{|c|}{$C_{D, 0.6}$} \\
\hline Ice Shape Fidelity & $C_{D, \min }$ & $\begin{array}{l}\qquad \Delta C_{D, \min } \\
\text { Low Fidelity - } \\
\text { High Fidelity }\end{array}$ & $\begin{array}{l}\text { Percent } \Delta C_{D, \min } \\
\text { (Low Fidelity - } \\
\text { High Fidelity) } \\
\text { / High Fidelity }\end{array}$ & $C_{D, 0.6}$ & $\begin{array}{c}\Delta C_{D, 0.6} \\
\text { Low Fidelity - } \\
\text { High Fidelity }\end{array}$ & $\begin{array}{l}\text { Percent } \Delta C_{D, 0.6} \\
\text { (Low Fidelity - } \\
\text { High Fidelity) } \\
\text { / High Fidelity }\end{array}$ \\
\hline Clean & 0.0078 & - & - & 0.0270 & - & - \\
\hline 3D High Fidelity & 0.0216 & - & - & 0.0640 & - & - \\
\hline 3D Smooth + Grit & 0.0182 & -0.0035 & $-16.0 \%$ & 0.0495 & -0.0145 & $-22.7 \%$ \\
\hline 3D Smooth & 0.0166 & -0.0051 & $-23.3 \%$ & 0.0469 & -0.0171 & $-26.7 \%$ \\
\hline
\end{tabular}



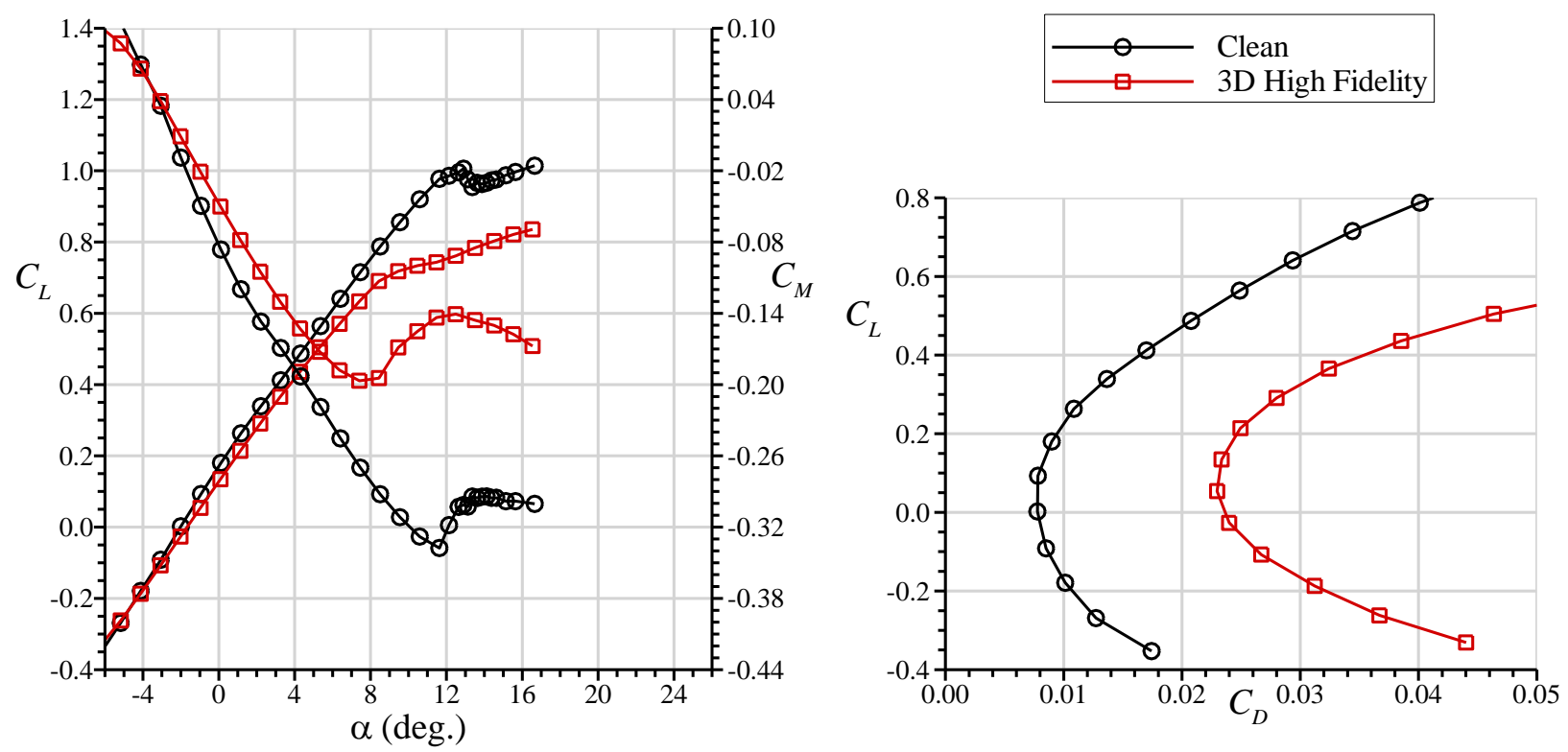

Figure 18. WSU Aerodynamic performance comparison between the three fidelity representations of the WB33 ice shape at $R e=2.4 \times 10^{6}, M=0.26$.
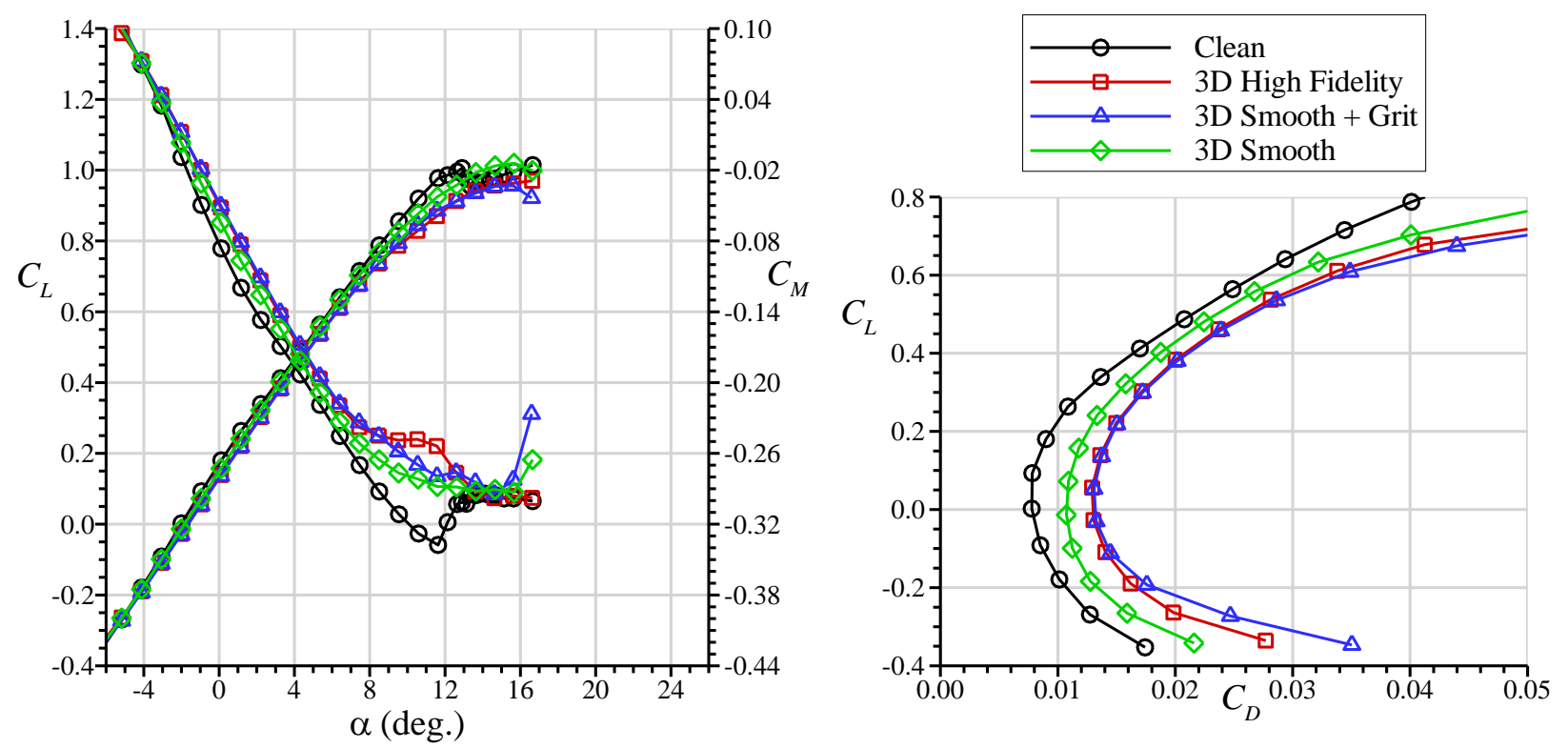

Figure 19. WSU Aerodynamic performance comparison between the three fidelity representations of the Streamwise/Rime ice shape at $R e=2.4 \times 10^{6}, M=0.26$.

The lift-based performance parameters were not well defined for the Streamwise/Rime ice shape, so they are not tabulated. As with the Maximum Scallop ice shape, the maximum lift coefficient is not clearly achieved, although the lift might be decreasing for all of the fidelities at the secondhighest angle of attack. Additionally, the local minimum value in the pitching moment defined about the quarter-chord of the mean aerodynamic chord is not at all well-defined for any of the 
Streamwise/Rime ice shape, so the usable lift could not definitively be established. The drag parameters were determined and are shown in Table 15. At this scale, the 3D smooth + grit ice shape matches the drag degradation of the high-fidelity ice shape well for both drag definitions. The 3D smooth + grit configuration increases the drag beyond the high-fidelity version slightly but less than at the F1 scale. The 3D smooth ice shape results in less of a drag penalty relative to the high-fidelity ice shape just as in the F1 case, but the difference is larger at the WSU scale.

Table 15. Summary of Streamwise/Rime Drag Performance Parameters for Various Fidelities at WSU scale at $R e=2.4 \times 10^{6}, M=0.26$.

\begin{tabular}{|c|c|c|c|c|c|c|}
\hline \multirow[b]{2}{*}{ Ice Shape Fidelity } & \multicolumn{3}{|c|}{$C_{D, \min }$} & \multicolumn{3}{|c|}{$C_{D, 0.6}$} \\
\hline & $C_{D, \min }$ & $\begin{array}{l}\qquad \Delta C_{D, \min } \\
\text { Low Fidelity - } \\
\text { High Fidelity }\end{array}$ & $\begin{array}{l}\text { Percent } \Delta C_{D, \min } \\
\text { (Low Fidelity - } \\
\text { High Fidelity) } \\
\text { / High Fidelity }\end{array}$ & $C_{D, 0.6}$ & $\begin{array}{c}\Delta C_{D, 0.6} \\
\text { Low Fidelity - } \\
\text { High Fidelity }\end{array}$ & $\begin{array}{l}\text { Percent } \Delta C_{D, 0.6} \\
\text { (Low Fidelity - } \\
\text { High Fidelity) } \\
\text { / High Fidelity }\end{array}$ \\
\hline Clean & 0.0078 & - & - & 0.0270 & - & - \\
\hline 3D High Fidelity & 0.0129 & - & - & 0.0330 & - & - \\
\hline 3D Smooth + Grit & 0.0131 & 0.0002 & $1.2 \%$ & 0.0341 & 0.0011 & $3.3 \%$ \\
\hline 3D Smooth & 0.0107 & -0.0022 & $-17.0 \%$ & 0.0298 & -0.0032 & $-9.7 \%$ \\
\hline
\end{tabular}

\section{F. Comparison of Ice-Shape Fidelity Effects at Different Scales}

In the following figures, the data collected at both wind tunnel facilities are compared. In Fig. 20, the usable lift coefficient is plotted for the only configuration for which data is available at both scales. The Maximum Scallop $\Delta C_{L, u s e}$ data are shown as a function of Reynolds number for a variety of Mach numbers with $\Delta C_{L, \text { use }}$ defined in the same way as in the previous tables, highfidelity $C_{L, \text { use }}$ subtracted from lower-fidelity $C_{L, \text { use }}$. The $C_{L, \max }$ values are not available at both scales, so these data represent the only lift-based comparison between the two scales currently available. For the WSU data on the plots, the two Reynolds numbers correspond to $M=0.17$ and 0.26 because Reynolds and Mach number are coupled. The F1 data correspond to a range of Mach numbers from 0.09 to 0.34 . The overall agreement in the effect on lift coefficient between the two scales is good. Some Reynolds number effects are evident in the case of the 3D smooth configuration. The difference in the usable lift coefficient increases with Reynolds number, and the data from WSU fall in line with the F1 data. In the case of the 3D smooth + grit configuration little evidence of Reynolds number effects are illustrated by the plot, and the data from WSU and F1 match reasonably well. In all of the data presented in this plot, some Mach number effects are evident by the spread in the data points at each Reynolds number. 


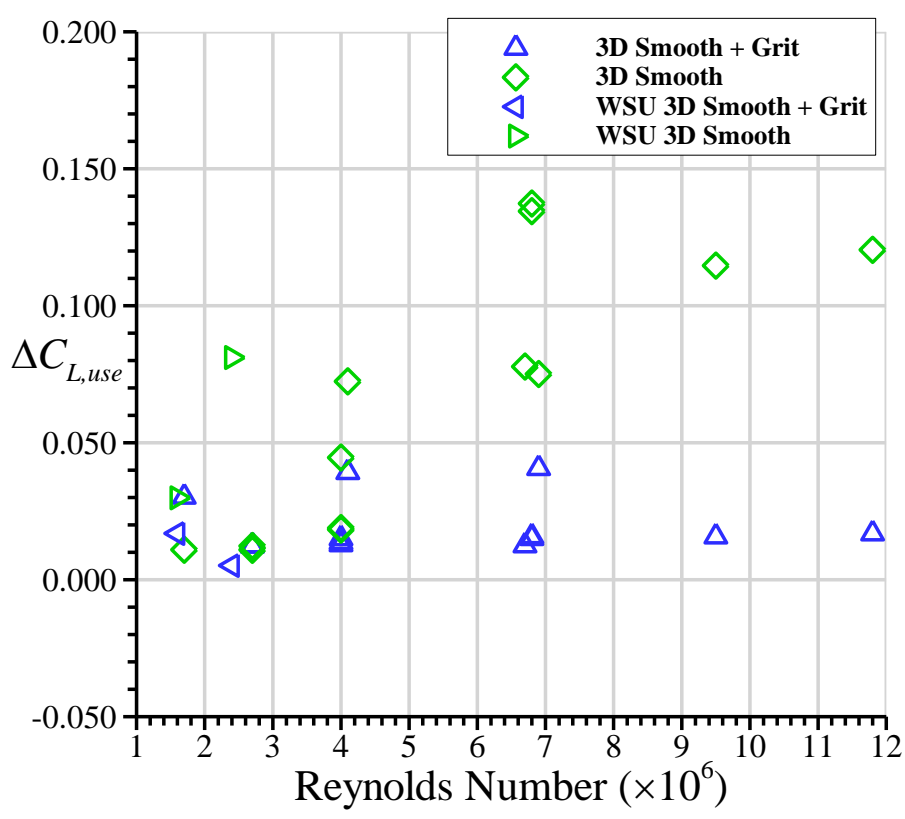

Figure 20. Lift coefficient differences for various fidelities of the Maximum Scallop ice shape tested at the WSU and F1 wind tunnel facilities. WSU Mach numbers range from $M=0.17$ to 0.26 , and F1 Mach numbers range from $M=0.09$ to 0.34 .

As discussed previously, both $C_{D, \min }$ and $C_{D, 0.6}$ have relatively weak dependence on Reynolds number and little variation with Mach number above 0.18. In Figs. 21, 22, and 23 $\Delta C_{D, \min }$ and $\Delta C_{D, 0.6}$ are plotted versus Reynolds number. The drag coefficient changes are defined as the drag coefficient for a particular fidelity ice shape minus the high-fidelity drag coefficient for that condition, resulting in mostly negative values. By plotting the data in this way as a change, differences in the precise magnitude of the drag between the two facilities do not affect the comparison. The Reynolds and Mach numbers for the WSU data are the same as described for Fig. 20, and the F1 data correspond to a range of Mach numbers from 0.18 to 0.34 . On each of the figures, the two data points at the lowest Reynolds number represent the WSU data. 

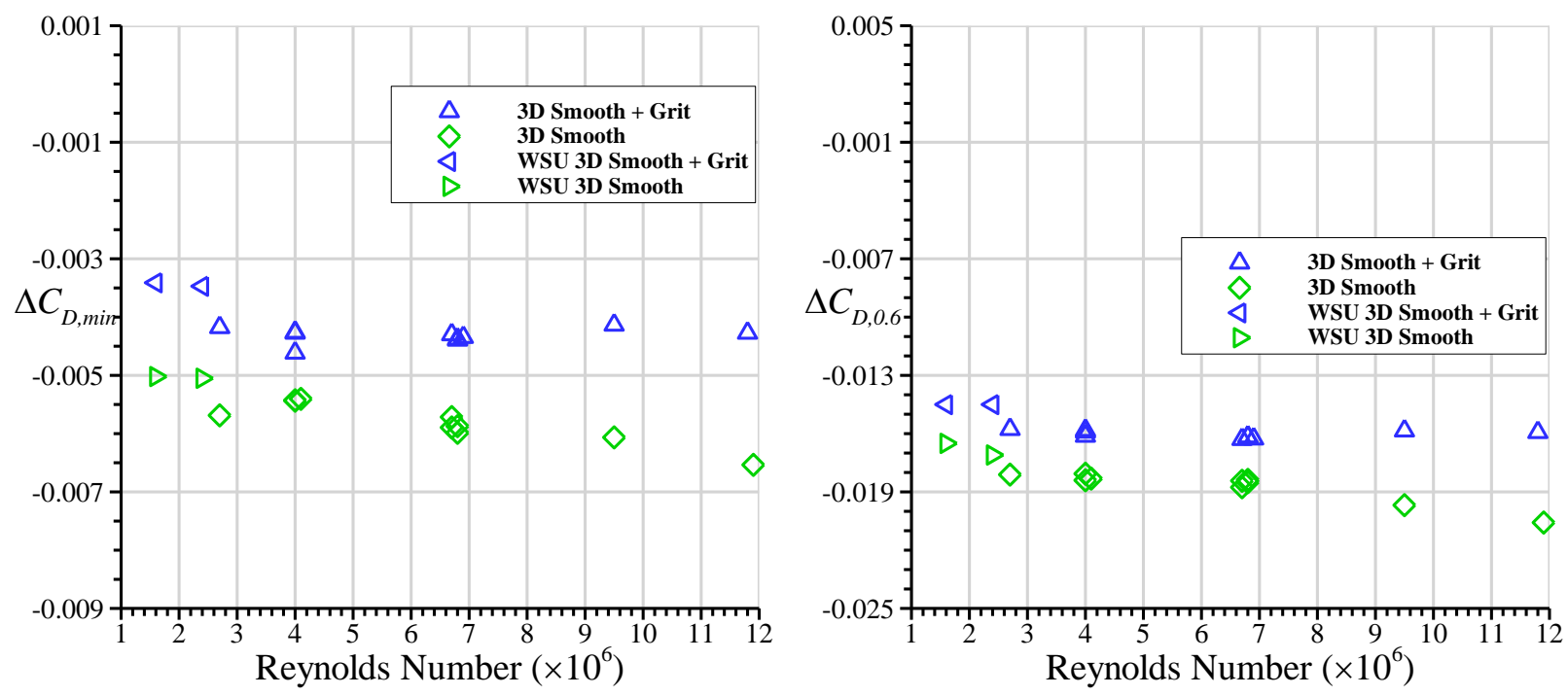

Figure 21. Drag coefficient differences from the 3D high fidelity configuration for various fidelities of the Maximum Scallop ice shape tested at the WSU and F1 wind tunnel facilities. WSU Mach numbers range from $M=0.17$ to 0.26 , and $F 1$ Mach numbers range from $M=0.18$ to 0.34 .
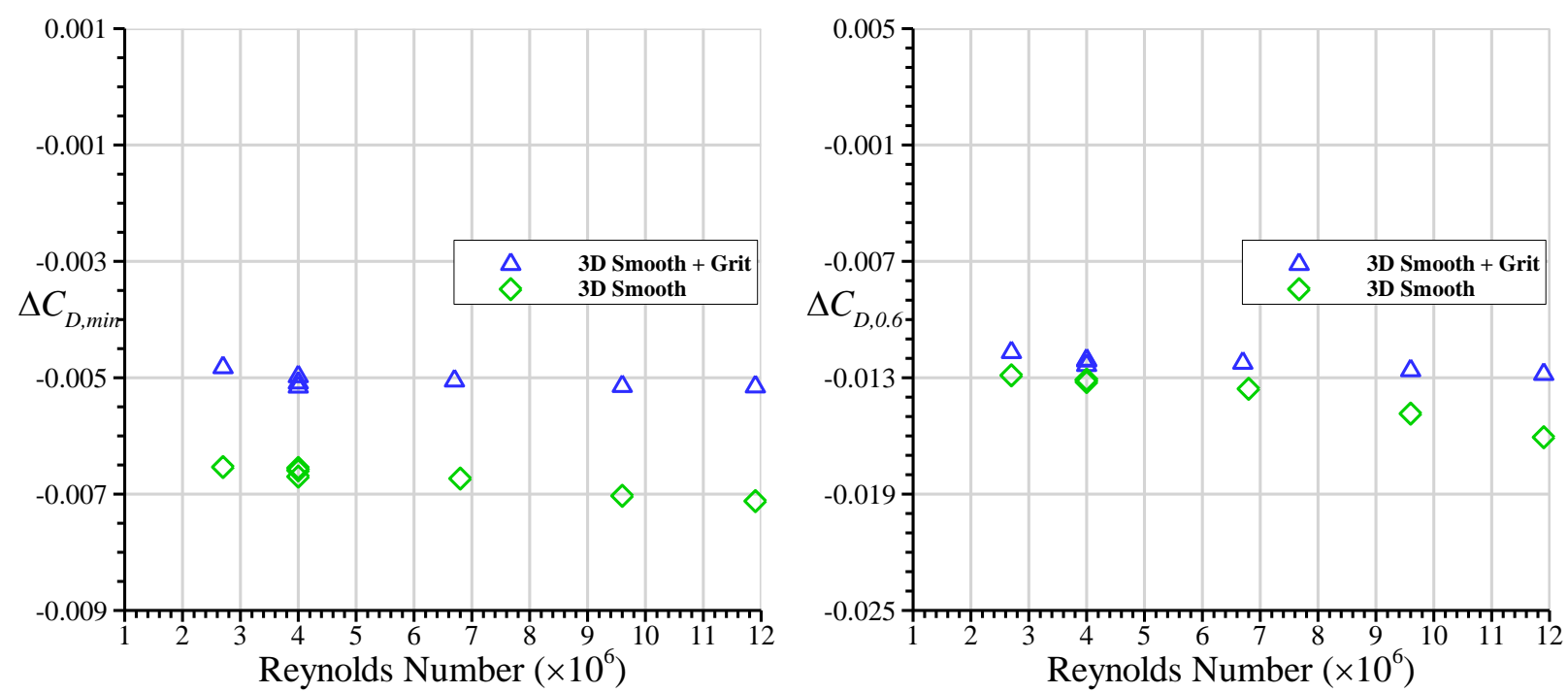

Figure 22. Drag coefficient differences from the 3D high fidelity configuration for various fidelities of the WB33 ice shape tested at the F1 wind tunnel facility. F1 Mach numbers range from $M=0.18$ to 0.34 . 

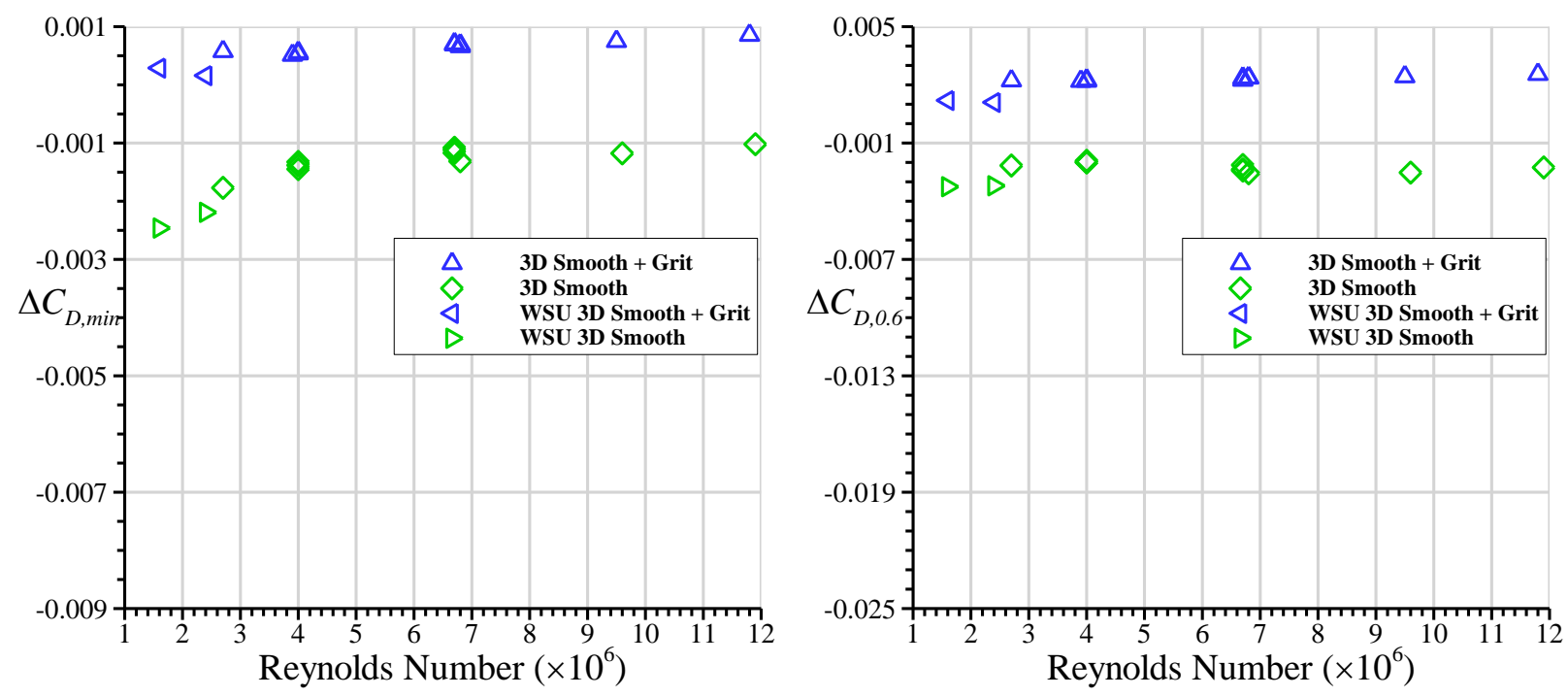

Figure 23. Drag coefficient differences from the 3D high fidelity configuration for various fidelities of the Streamwise/Rime ice shape tested at the WSU and F1 wind tunnel facilities. WSU Mach numbers range from $M=0.17$ to 0.26 , and $F 1$ Mach numbers range from $M=0.18$ to 0.34 .

The data sets do not quite overlap, but the agreement is good for most of the cases. For all of the cases shown in Figs. 21, 22, and 23, a few general trends can be observed. The Reynolds number effects on the drag differences for the 3D smooth + grit ice shapes are essentially nonexistent. For the Maximum Scallop and WB33 ice shapes, the drag differences for the 3D smooth ice shapes exhibit a slight linear decrease with increasing Reynolds number. The Streamwise/Rime ice shape shows no Reynolds number effects for the $\Delta C_{D, 0.6}$ values for either fidelity. The WSU data appear slightly high for the Maximum Scallop ice shape and slightly low for the Streamwise/Rime ice shape relative to the F1 data. The lower fidelity versions of the WB33 ice shape were not available for testing at WSU. Even though the data sets from WSU and F1 do not precisely match, the differences are small. For example, the 3D smooth + grit maximum scallop ice shape $\Delta C_{D, 0.6}$ value from WSU is only 14 drag counts higher than the associated value from F1. Considering the overall impact of these ice shapes on the wing performance, those drag differences are approximately $10 \%$ of the overall drag impact of the ice shape on the wing indicating that lower-Reynolds number facilities can be useful for studying the drag impact of these various fidelity ice-shape representations. Once additional ice shapes have been tested in both facilities, further comparisons can be completed to assess whether the drag performance trends identified in this section can be extrapolated to additional swept-wing ice shapes that are 
tested in different Reynolds number facilities at different scales. Those additional studies may lead to more definitive conclusions regarding the usefulness of extrapolating the results from these low-Reynolds number facilities to flight Reynolds numbers.

Based on the results presented here, there are a number of suggested future studies. Ice shapes with greater fidelity variations need to be tested in both low- and high-Reynolds number facilities in order to expand the available data sets for comparison as in the preceding figures. The impact of the scalloped ice shapes on the flowfield requires additional data with different size and scallop spacing. These ice shapes could be generated from other icing tests or artificially modeled with defined scallop parameters. Other grit roughness studies could be performed to investigate whether larger grit would add sufficient three dimensionality to the 3D smooth ice shapes to match the performance degradation produced by the high-fidelity ice shapes. Additionally, ice shapes from icing simulation tools could also be tested.

\section{Summary and Conclusion}

This paper primarily presents results from high-Reynolds number aerodynamic testing of a swept wing with various full-span, artificial ice shapes with an emphasis on exploring the different fidelities by which ice shapes can be represented. Additionally, low-Reynolds number aerodynamic data are also presented for comparison to the high-Reynolds number data for ice shape configurations which were tested in the two different facilities. These high-Reynolds number tests were conducted at the ONERA F1 wind tunnel using a 13.3\% scale semispan wing model of the CRM65, based on the Common Research Model. The lower-Reynolds number tests were conducted at the WSU Beech wind tunnel using an $8.9 \%$ scale model of the same wing. The two models were geometrical identical except for the scale difference. The model for the F1 wind tunnel is $50 \%$ larger than the model for the WSU wind tunnel. During the wind-tunnel test campaigns, three ice shapes and the clean leading-edge model were tested at a variety of flow conditions, and aerodynamic performance parameters were recorded. Coefficients of lift, drag, and pitching moment along with surface pressures were acquired for angle-of-attack sweeps. The data presented in this work were collected over the range of Reynolds numbers from of $2.7 \times 10^{6}$ to $11.9 \times 10^{6}$ and a Mach number range of 0.18 to 0.34 in the F1 facility and at $R e=1.6 \times 10^{6}, M=0.17$ and $\operatorname{Re}=2.4 \times 10^{6}, M=0.26$ in the WSU facility. 
The high-fidelity ice shapes investigated were based on a series of icing wind tunnel tests in the NASA IRT. These tests at full scale provided 3-D laser scans of the ice accretions at three spanwise stations along the wing. Based on those laser scans, full-span ice shapes were developed, and these ice shapes are called "3D high fidelity" as they capture the highly three-dimensional geometry properties of the ice shapes. Lower fidelity representations can be developed from these full-span, high-fidelity ice shapes. "3D smooth" ice shapes retain the overall spanwise variation in ice-shape size, but do not have any of the gaps or scallops along the span. These ice shapes can have grit roughness applied to them to produce another category of ice shapes called "3D smooth + grit." The three specific ice shapes for which multiple fidelity variations have been produced are named Maximum Scallop, WB33, and Streamwise/Rime. Both the Maximum Scallop and WB33 ice shapes have substantial three dimensionality in that they have gaps in the ice shapes as a function of span. The size and shape of these gaps varies across the span, and the resulting features are typically called scallops. The Streamwise/Rime ice shape does not exhibit the scallop features, and the cross section changes more continuously across the span.

The effect of ice-shape fidelity was investigated for these three iced configurations on the swept wing, and the aerodynamic performance was compared to the wing clean. The high-fidelity ice shapes had a substantial impact on the performance of the wing resulting in reduced lift, reduced stall angle, and increased drag. Other investigations of the same data set showed that the impact of Reynolds and Mach number was relatively small for the iced configurations, so only the highest Reynolds number cases were thoroughly examined in this work. In order to better quantify the impact of the iced configurations on the wing, additional performance parameters were applied to the data beyond standard values of maximum lift coefficient and minimum drag coefficient. The parameters are the usable lift coefficient, defined as the lift at the first local minimum in pitching-moment coefficient referenced to the quarter-chord of the mean aerodynamic chord, and the drag coefficient at a specified lift coefficient. For this work, that lift coefficient was selected to be equal to 0.6. These performance parameters are consistent with other swept-wing literature and have also been applied to other studies of this specific data set.

The effects of the fidelity representation for the ice shapes on the wing performance were similar between the two ice-shape configurations that are highly three dimensional. The 3D highfidelity ice shape had the largest impact on both lift and drag. The effects of the 3D smooth ice shape were significantly reduced relative to the high-fidelity shape, and the 3D smooth plus grit 
shape fell between them. These results indicate that, for highly three-dimensional ice formations like those found on swept wings, the smooth representations are not conservative approximations of the icing impact even when grit roughness is added to the ice shape. Generalizing for the Maximum Scallop and WB33 ice shapes, the 3D smooth fidelity captures approximately $30 \%$ less drag than the high-fidelity ice shape, and the 3D smooth + grit fidelity captures $25 \%$ less drag. The Streamwise/Rime ice shape followed a different pattern. The 3D smooth fidelity with grit roughness added to the ice shape had a larger impact on the drag performance parameters than the high fidelity. The smooth ice shape with grit increased the drag by approximately $10 \%$ compared to the high fidelity ice shape. The 3D smooth ice shape without the grit had a smaller impact on the drag parameters consistent with the more three dimensional ice shapes.

The effects of the varied-fidelity ice shapes on the drag were compared over a wide range of Reynolds numbers encompassing two different wind tunnels. Data collected in the lowReynolds number WSU facility were compared to the data collected in the high-Reynolds number F1 facility. The usable lift coefficient was compared between the two different facilities for the Maximum Scallop ice shape, and the agreement in the data was good. The difference between the drag measured for each low-fidelity ice shape and the drag measured for the high-fidelity representation were plotted against Reynolds number for all the configurations for which data are available. For all the ice-shape fidelities and each of the different ice shapes, the agreement between the two facilities was quite good which indicates that lower-Reynolds number facilities can be useful for studying the drag effects of these various-fidelity ice shapes on swept wings. Neither drag-based performance parameter showed significant Reynolds number effect, and the 3D smooth + grit ice shapes exhibited no variation with Reynolds number. More ice shapes should be tested and compared using similar metrics in order to draw more definitive conclusions regarding the usefulness of extrapolating results from low-Reynolds number facilities to flight Reynolds numbers.

The results presented in this paper have demonstrated that the fidelity by which sweptwing ice shapes are represented has a substantial impact on the aerodynamic performance of that wing with the artificial ice shape. Additional data sets are needed in both low- and high-Reynolds number facilities. Swept-wing icing offers a particularly challenging problem for aircraft manufactures, and the suggested future studies in Section III.F. will provide a better understanding of the impact of and flowfields associated with these ice shapes. 


\section{Acknowledgements}

The authors gratefully acknowledge the assistance of many other individuals and organizations that made this work possible. Specific contributors to conducting these wind tunnel test campaigns and understanding the acquired data were Mark Potapczuk at NASA Glenn Research Center, Kevin Ho, Stephanie Camello, and Navdeep Sandhu at the University of Washington, and Timothy Smith at the FAA. William Yoshida, an undergraduate student at the University of Illinois, wrote the computer code that generated the data for the surface-pressure contour plots. He also then created many of the figures necessary for this work. The engineers and technicians at both the ONERA F1 wind tunnel and the WSU Beech wind tunnel were extraordinarily helpful in keeping the tests running smoothly and efficiently. The NASAsupported portion of this research was originally funded under the Atmospheric Environment Safety Technologies Project of the Aviation Safety Program with continued support under the Advanced Air Transport Technology and Aeronautics Evaluation and Test Capabilities Projects of the Advanced Air Vehicles Program. The Universities of Washington and Illinois are funded for this program by FAA grant 15-G-009 with support from Dr. James T. Riley.

\section{References}

${ }^{1}$ Broeren, A.P., Potapczuk, M.G., Riley, J.T., Villiedieu, P., Moens, F., and Bragg, M.B., "Swept-Wing Ice Accretion Characterization and Aerodynamics," AIAA Paper 2013-2824, June 2013, also NASA/TM-2013216555, Sept. 2013.

${ }^{2}$ Bragg, M.B., Broeren, A.P., and Blumenthal, L.A., "Iced-Airfoil Aerodynamics," Progress in Aerospace Sciences, Vol. 41, No. 5, July 2005, pp. 323-418.

${ }^{3}$ Fujiwara, G.E.C., Bragg, M.B., Camello, S.C., and Lum, C., "Computational and Experimental Ice Accretions of Large Swept Wings in the Icing Research Tunnel,” AIAA Paper 2016-3734, June 2016.

${ }^{4}$ Radenac, E., "Validation of a 3D Ice Accretion Tool on Swept Wing of the SUNSET2 Program," AIAA Paper 2016-3735.

${ }^{5}$ Broeren, A.P., Potapczuk, M.G., Lee, S., Malone, A.M., Paul, B.P., Jr., and Woodard, B.S., "Ice-Accretion Test Results for Three Large-Scale Swept-Wing Models in the NASA Icing Research Tunnel," AIAA Paper 2016-3733, June 2016; also NASA/TM-2016-219137, Sept. 2016.

${ }^{6}$ Broeren, A.P., Addy, H.E., Jr., Bragg, M.B., Busch, G.T., Guffond, D., and Montreuil, E., “Aerodynamic Simulation of Ice Accretion on Airfoils," NASA/TP_2011-216929, June 2011.

7 Broeren, A.P, Addy, H.E., Jr., Lee, S., Monastero, M.C., "Validation of 3-D Ice Accretion Measurement Methodology for Experimental Aerodynamic Simulation," NASA/TM-2015-218724, July 2015.

${ }^{8}$ Vassberg, J.C., DeHann, M.A., Rivers, S.M., and Wahls, R.A., "Development of a Common Research Model for Applied CFD Validation Studies," AIAA Paper 2008-6919, Aug. 2008. 
9 Rivers, M.B., and Dittberner, A., "Experimental Investigation of the NASA Common Research Model," AIAA Paper 2010-4218, June 2010.

${ }^{10}$ Rivers, M.B., and Dittberner, A., "Experimental Investigations of the NASA Common Research Model in the NASA Langley National Transonic Facility and the NASA Ames 11-Ft Transonic Wind Tunnel," AIAA Paper 2011-1126, Jan. 2011.

${ }^{11}$ Vassberg, J. C., Tinoco, E. N., Mani, M., Rider, B., Zickuhr, T., Levy, D.W., Brodersen, O., Eisfeld, B., Crippa, S., Wahls, R. A., Morrison, J. H., Mavriplis, D.J., and Murayama, M., "Summary of the Fourth AIAA CFD Drag Prediction Workshop," AIAA Paper 2010-4547, June 2010.

${ }^{12}$ Fujiwara, G. E., Woodard, B. S., Wiberg, B., Mortonson, A. J., and Bragg, M. B., “A Hybrid Airfoil Design Method for Icing Wind Tunnel Tests," Proceedings of the 5th AIAA Atmospheric and Space Environments Conference, AIAA Paper 2013-2826, San Diego, CA, June 2013.

${ }^{13}$ Broeren, A.P., Woodard, B.S., Diebold, J.M., and Moens, F., "Low-Reynolds Number Aerodynamics of an 8.9\% Scale Semispan Swept Wing for Assessment of Icing Effects," AIAA Paper 2017-4372; also NASA/TM-2017219533, July 2017.

${ }^{14}$ Camello, S.C., Bragg, M.B., Broeren, A.P., Lum, C.W., Woodard, B.S., and Lee, S., "Effect of Ice Shape Fidelity on Swept-Wing Aerodynamic Performance," AIAA Paper 2017-4373, June 2017.

${ }^{15}$ Lum, C.W., Sandhu, N., Diebold, J.M., Woodard, B.S., and Bragg, M.B., "The Application of a Five-Hole Probe Wake-Survey Technigue to the Study of Swept Wing Icing Aerodynamics," AIAA Paper 2017-4374, June 2017.

${ }^{16}$ Broeren, A.P., Lee, S., Woodard, B.S., Lum, C.W., Smith, T.G., "Independent Effects of Reynolds and Mach Numbers of the Aerodynamics of an Iced Swept Wing," AIAA $10^{\text {th }}$ Atmospheric and Space Environments Conference, Atlanta, GA, June 25-29, 2018 (submitted for publication), 2018.

${ }^{17}$ Lee, S., Broeren, A.P., Woodard, B.S., Lum, C.W., and Smith, T.G., "Comparison of Iced Aerodynamic Measurements on Swept Wing from Two Wind Tunnels," AIAA $10^{\text {th }}$ Atmospheric and Space Environments Conference, Atlanta, GA, June 25-29, 2018 (submitted for publication), 2018.

${ }^{18}$ Sandhu, N., Soltani, M.R., Bragg, M.B., Lum, C.W., Woodard, B.S., Broeren, A.P., and Lee, S., "Effect of Simulated Scalloped Ice on the Aerodynamics of a Swept-Wing at Low-Reynolds Number,"AIAA $10^{\text {th }}$ Atmospheric and Space Environments Conference, Atlanta, GA, June 25-29, 2018 (submitted for publication), 2018.

19 Woodard, B.S., Broeren, A.P., Diebold, J.M., and Bragg, M.B., "Preliminary Testing of Low Reynolds Number Aerodynamics for a Swept Wing with Artificial Ice Roughness,” DOT/FAA/TC-17/48, Sept. 2017.

${ }^{20}$ Barlow, J.B., Rae, W.H., Jr., Pope, A., Low-Speed Wind Tunnel Testing, John Wiley \& Sons, Inc., $3^{\text {rd }}$ Ed., 1999, pp. 367-425.

21 "Data Reduction System: Boundary Corrections Three Dimensional Aircraft," Walter H. Beech Wind Tunnel Engineering Process Description, April 2014.

${ }^{22}$ Addy, H.E., Jr., and Chung, J.J., "A Wind Tunnel Study of Icing Effects on a Natural Laminar Flow Airfoil," AIAA Paper 2000-0095, Jan. 2000; also NASA/TM-2000-209775, Jan. 2000.

23 Addy, H.E., Jr., Broeren, A.P., Zoeckler, J.G., and Lee, S., "A Wind Tunnel Study of Icing Effects on a Business Jet Airfoil,” AIAA Paper 2003-0727, Jan. 2003; also NASA/TM-2003-212124, Feb. 2003.

${ }^{24}$ Broeren, A.P., Bragg, M.B., and Addy, H.E., Jr., "Effect of Intercycle Ice Accretions on Aerodynamic Performance," Journal of Aircraft, Vol. 41, No. 1, Jan.-Feb. 2004, pp 165-174. 
25 Broeren, A.P., Bragg, M.B., Addy, H.E., Jr., Lee, S., Moens, F., and Guffond, D., "Effect of High-Fidelity Ice Accretion Simulations on the Performance of a Full-Scale Airfoil Model," Journal of Aircraft, Vol. 47, No. 1, Jan.Feb. 2010, pp. 240-254; also NASA/TM-2010-216344, Jun. 2010.

${ }^{26}$ Camello, S.C., Lee, S., Lum, C.W., and Bragg, M.B., "Generation of Fullspan Leading-Edge 3D Ice Shapes for Swept-Wing Aerodynamic Testing,” AIAA Paper 2016-3737, June 2016.

27 Federal Aviation Administration, Advisory Circular AC 25-25A, Oct. 27, 2014.

28 Furlong, G.C., and McHugh, J.G., "A Summary and Analysis of the Low-speed Longitudinal Characteristics of Swept Wings at High Reynolds Number, NACA-TR-1339, Jan. 1957.

${ }^{29}$ Lynch, F.T., and Khodadoust, A., "Effects of Ice Accretions on Aircraft Aerodynamics," Progress in Aerospace Sciences, Vol. 37, No. 8, Nov. 2001, pp. 669-767. 